\title{
Associations between circadian preferences, sleep quality, dissociation, post-traumatic cognitions, and post-traumatic stress disorder (PTSD) among incarcerated offenders
}

\author{
Özlem Fidan Acar ${ }^{1}$, Selahiddin Öğülmüş², Murat Boysan ${ }^{3 *}$ \\ ${ }^{1}$ Van M Type Correctional Institution, Department of Penalty and Arresting Houses, Republic of Turkey Ministry of Justice, Van, Turkey \\ ${ }^{2}$ Department of Guidance and Psychological Counseling, Faculty of Educational Sciences, Ankara University, Ankara, Turkey \\ ${ }^{3}$ Department of Psychology, Faculty of Social Sciences, Van Yüzüncü Yıl University, Van, Turkey
}

\begin{abstract}
The aim of this study was to explore whether DSM-5 posttraumatic stress disorder (PTSD) dissociative subtype could be differentiated from non-dissociative PTSD caseness in sleep disturbances, circadian preferences, and posttraumatic cognitions. We also investigated associations of dissociation, sleep quality, insomnia, circadian preferences, and traumarelated negative cognitions with DSM-5 PTSD caseness among prisoners. Data from 399 volunteers (mean age: $34.54 \pm 9.93$ years) were collected. Using the symptoms clusters measured by the PTSD Checklist for DSM-5 (PCL-5) and Dissociative Experiences Scale (DES), the participants were classified into four subgroups: no dissociation or PTSD, pure dissociative, pure PTSD, and dissociative PTSD. Differences in scale scores across four groups were evaluated using one-way analysis of variance. Logistic regression analysis was utilized to determine predictors of DSM-5 PTSD caseness. Participants with dissociative PTSD reported significantly greater posttraumatic stress reactions in terms of PTSD and dissociative symptomatology, greater number of prior trauma exposure, greater scores on posttraumatic negative cognitions, and a tendency to have eveningness diurnal preferences in comparison to those prisoners classified into other three subgroups (no dissociation or PTSD, pure dissociative, and pure PTSD). However, sleep disturbances in terms of insomnia and poor sleep quality were found to be pronounced among prisoners with PTSD irrespective of levels of dissociation. Dissociative symptomatology, insomnia and poor sleep quality significantly contributed to probable PTSD caseness. Dissociation and sleep disturbances appear to be hallmark for PTSD among prisoners.
\end{abstract}

Keywords: Dissociative experiences, diurnal preferences, dissociative-PTSD subtype, sleep dissociation

\section{INTRODUCTION}

Post-traumatic stress disorder (PTSD) is a clinical syndrome characterized by intrusions, avoidance, and

*Correspondence: boysan.muratagmail.com

Murat Boysan, PhD*, Department of Psychology, Faculty of Social

Sciences, Van Yüzüncü Yıl University, Van, Turkey.

Telephone: +904322251051 / 23211 Fax: +90 4322551188

Received: 27 September 2018 Accepted: 22 October 2018

Sleep and Hypnosis

Journal homepage:

www.sleepandhypnosis.org

ISSN: 2458-9101 (Online) negative cognitive and emotional changes and increased arousal and startle states that persist for more than 1-month immediate to exposure to an adverse life event (American Psychiatric Association, 2013). Trauma exposure is not rare in general population and estimated lifetime prevalence of posttraumatic stress disorder (PTSD) was $8.7 \%$ in the United States population (Kilpatrick et al., 2013).

Individuals involved in the criminal justice system and those with a mental health disorder are at higher risk of trauma exposure, and development and persistence of PTSD compared to prevalence rates in general 
population (Browne, Miller, \& Maguin, 1999; Choe, Teplin, \& Abram, 2008; Maxfield \& Widom, 1996; Mueser et al., 2004; Teplin, McClelland, Abram, \& Weiner, 2005). Therefore, PTSD has been increasingly recognized as a major health concern among prison inmates that leads to substantial suffering, debilitating effects, and health care costs in that special population (Goff, Rose, Rose, \& Purves, 2007; Moloney, van den Bergh, \& Moller, 2009). There has been a vast body of evidence documenting the high prevalence rates among those prisoners with PTSD far exceeds general population, ranging from 3.6\% to 75.3\% (Akyuz, Kugu, Sar, \& Dogan, 2007; Anderson, Geier, \& Cahill, 2016; Blonigen, Sullivan, Hicks, \& Patrick, 2012; Briere, Agee, \& Dietrich, 2016; Cusack, Herring, \& Steadman, 2013; Flatt, Williams, Barnes, Goldenson, \& Ahalt, 2017; Gibson et al., 1999; Gosein, Stiffler, Frascoia, \& Ford, 2016; Henrichs \& Bogaerts, 2012; Huang, Zhang, Momartin, Cao, \& Zhao, 2006; Jordan, Schlenger, Fairbank, \& Caddell, 1996; Komarovskaya, Loper, Warren, \& Jackson, 2011; Ruzich, Reichert, \& Lurigio, 2014; Teplin, Abram, \& McClelland, 1996; Warren, Loper, \& Komarovskaya, 2009), in which the wide variation in the rates of probable PTSD caseness among inmate samples appears to be the by-product of distinctions in assessment approach, screening tools and PSTD diagnostic criteria built-on different diagnostic systems. However, incarceration, trauma exposure and lifetime and current PTSD co-vary far more frequently even when controlling for socio-demographic covariates among incarcerated people (Anderson et al., 2016).

Given the compelling evidence, sleep is critical for emotion and behavioral regulation (Goldstein \& Walker, 2014; Harvey, 2008). Sleep disturbance is very common in PTSD (Maher, Rego, \& Asnis, 2006). Sleep disturbances early after trauma exposure feature an increased risk of meeting criteria for PTSD (Breslau, Roth, Rosenthal, \& Andreski, 1996; Bryant, Creamer, O'Donnell, Silove, \& McFarlane, 2010; Bryant, Harvey, Guthrie, \& Moulds, 2000; Koren, Arnon, Lavie, \& Klein, 2002; Mellman, Pigeon, Nowell, \& Nolan, 2007; Wright et al., 2011). PTSD patients frequently report poor sleep quality, chronic nightmares, sleep terrors, acting out dreams, sleep movement disorders, and sleep-disordered breathing
(Germain, Buysse, Shear, Fayyad, \& Austin, 2004; Germain, Hall, Krakow, Katherine Shear, \& Buysse, 2005; Krakow et al., 2004; Krakow et al., 2001; Krakow et al., 2006; Williams, Collen, Orr, Holley, \& Lettieri, 2015). Sleep disturbances contribute to manifestation of a more complicated clinical expression of symptoms in PTSD, such as comorbid depression (Krakow et al., 2000), psychiatric distress (Krakow et al., 2007), heightened suicidality and self-injurious behavior (Betts, Williams, Najman, \& Alati, 2013; Malik et al., 2014; Pigeon, Pinquart, \& Conner, 2012; Short, Ennis, et al., 2015), greater anxiety sensitivity (Babson, Boden, Woodward, Alvarez, \& BonnMiller, 2013), increased alcohol and drug use (Nishith, Resick, \& Mueser, 2001; Saladin, Brady, Dansky, \& Kilpatrick, 1995; Short, Babson, Boden, \& Bonn-Miller, 2015), and decreased quality of life and functioning (Clum, Nishith, \& Resick, 2001; Giosan et al., 2015; Krakow, Melendrez, Johnston, et al., 2002; Short, Allan, \& Schmidt, 2017). Poor sleep can significantly contribute to next day affective deterioration, such as increased PTSD symptoms and negative affect (Short et al., 2017; Short et al., 2016). Most notably, sleep disturbances do not remit spontaneously or through treatment and are closely tied to refractory PSTD symptoms (Wright et al., 2011). On the other hand, there have been relatively few studies addressing linkages between circadian preferences and PTSD. It was found that eveningness diurnal preferences are significantly associated with severe PTSD among survivors of the Great Hanshin-Awaji Earthquake (Kuroda, Wada, Takeuchi, \& Harada, 2013; Wada, Kuroda, Nakade, Takeuchi, \& Harada, 2014). Dell'Osso et al. (2014) identified that dysregulation of circadian/ seasonal rhythm and vegetative function as indexed by Mood Spectrum-Self Report (Dell'Osso et al., 2002) was substantial correlate of suicidality in DSM-5 PTSD caseness. Eveningness diurnal preferences were found to be associated with difficulties in emotion regulation and sleep disturbances among those military veterans with varying degrees of PTSD (Hasler, Insana, James, \& Germain, 2013).

Arousal regulation and memory consolidation both of which are functions of sleep appear to be crucial in determining the onset and persistence of PTSD (Levin \& 
Nielsen, 2007; Walker \& van der Helm, 2009). Undiminished noradrenergic activity at night, fragmented rapid eye movement (REM) sleep and increased noradrenergic activity during REM sleep phase has found to be significantly linked to increased risk for onset of PTSD and poorer clinical outcomes (Breslau et al., 2004; Habukawa, Uchimura, Maeda, Kotorii, \& Maeda, 2007; Mellman, Bustamante, Fins, Pigeon, \& Nolan, 2002; Mellman, Knorr, Pigeon, Leiter, \& Akay, 2004). A metaanalytic review of 20 studies concerning abnormalities in polysomnograph records reported that PTSD patients are characterized by prolonged stage 1 sleep, less slow wave sleep, and greater rapid-eye movement density compared to people without PTSD (Kobayashi, Boarts, \& Delahanty, 2007). Neuroimaging studies depicted that PTSD is associated with increased REM sleep limbic and paralimbic metabolism (Ebdlahad et al., 2013; Germain, Mammen, Price, \& Nofzinger, 2011).

Dissociation involves discontinuity in the normal integration of psychological functioning, including consciousness, perception, memory, identity, affect, and motor control (Boysan, Yildirim, Besiroglu, Kefeli, \& Kagan, 2018; Krause-Utz, Frost, Winter, \& Elzinga, 2017; Spiegel et al., 2011). Dissociation is a multifaceted phenomenon, capturing a wide range of psychological symptoms: absorption and imaginative involvement, dissociative amnesia, and depersonalization / derealization (Armour, Contractor, Palmieri, \& Elhai, 2014; C. A. Ross, Joshi, \& Currie, 1991; Sanders \& Green, 1994; Soffer-Dudek, Lassri, Soffer-Dudek, \& Shahar, 2015; Stockdale, Gridley, Balogh, \& Holtgraves, 2002). Dissociation is a mundane human experience almost ubiquitous in nonclinical populations and considered to be a buffering response to intense unbearable emotions arise from adverse life events (Butler, Duran, Jasiukaitis, Koopman, \& Spiegel, 1996; Oathes \& Ray, 2008); contrarily, heightened levels of symptomatology evolves into pathological dissociation that appears to have considerable negative impact exert on affective-cognitive functioning (Boysan, 2014, 2016). Pathological dissociation is a transdiagnostic clinical phenomenon prominent in dissociative disorders, PTSD, obsessivecompulsive disorder, and borderline personality disorder
(Boysan et al., 2018; Gleaves, May, \& Cardena, 2001; Haaland \& Landro, 2009; Kadak, Nasiroglu, Boysan, \& Aydin, 2013; Tapanci, Yildirim, \& Boysan, 2018).

Trauma-induced stress and nightmares are critical in the development and persistence of dissociative symptoms (Agargun, Kara, Ozer, Selvi, Kiran, \& Kiran, 2003; Agargun, Kara, Ozer, Selvi, Kiran, \& Ozer, 2003; Cheung, 2012; Semiz, Basoglu, Ebrinc, \& Cetin, 2008). In keeping with the continuity hypothesis, Watson (2001) suggested that dissociative experiences are by-product of labile sleep-wake cycle. Prior trauma was demonstrated to have significant dose-response relationship with dissociation through sleep impairment (van Heugten-van der Kloet, Merckelbach, Giesbrecht, \& Broers, 2014). On the other hand, people more prone to dissociation easily overwhelm in the face of daily stressful life events and report more severe sleep-related problems (SofferDudek \& Shahar, 2009, 2011). Particularly absorption and/or fantasy proneness have been identified as significant correlates of sleep disturbance (Knox \& Lynn, 2014; Simor, Csóka, \& Bódizs, 2010; Soffer-Dudek et al., 2017; Yıldırım, Boysan, \& Yılmaz, 2017).

Dissociative symptomatology has long been construed as a salient feature of trauma-induced reactions in the wake of a traumatic experience and identified as a risk factor for development and maintenance of PTSD (Bryant, 2005; Ozer, Best, Lipsey, \& Weiss, 2003; van der Hart, van Ochten, van Son, Steele, \& Lensvelt-Mulders, 2008). Recent research interest has placed importance on explicating the role of dissociation in the underlying mechanisms of post-traumatic stress response and identifying a dissociative sub-type through classifying PTSD afflicted individuals into homogenous subgroups. Research utilizing taxometric analysis has identified two to five distinct profiles of which a subgroups of those individuals with PTSD was characterized by a dissociative PTSD profile (Armour, Karstoft, \& Richardson, 2014; Blevins, Weathers, \& Witte, 2014; Frewen, Brown, Steuwe, \& Lanius, 2015; Mullerova, Hansen, Contractor, Elhai, \& Armour, 2016; Steuwe, Lanius, \& Frewen, 2012; Wolf, Lunney, et al., 2012; Wolf, Miller, et al., 2012; Wolf et al., 2017). Recent revision of the Diagnostic and Statistical Manual of Mental Disorders 
(DSM-5) included a dissociative subtype of PTSD, marked by dissociative responses to cues of traumatic events in the form of depersonalization and/or derealization (American Psychiatric Association, 2013). Associated features of dissociative subtype of PSTD include heightened trauma-related symptomatology, increased comorbid psychiatric conditions, more frequency of sleep disturbances and hostility, and multiple traumatization (Armour, Elklit, Lauterbach, \& Elhai, 2014; Hansen, Ross, \& Armour, 2017; van Huijstee \& Vermetten, 2017).

Long-term incarceration probably reflects a traumatization on its own and is associated with PTSD as well as other stressor related disorders which in turn leads to behavioral problems including specifically substance use disorder and aggression, more trauma exposure and criminal recidivism (Ardino, 2012; Cusack et al., 2013; Dudeck et al., 2011; Maschi, Gibson, Zgoba, \& Morgen, 2011; Spitzer et al., 2001). In cross-sectional studies undertaken on community dwelling samples, PTSD has been consistently found to be associated with grater rates of self-reported contacts with the criminal justice system (Collins \& Bailey, 1990; Donley et al., 2012). More recent research on released prisoners with PTSD showed that a majority of those justice-involved persons with PTSD were more likely to be rearrested within the same year for a new felony charge relative to prisoners without PTSD (Kaba et al., 2015; Peller, Najavits, Nelson, LaBrie, \& Shaffer, 2010; Sadeh \& McNiel, 2015), indicating that jail inmates with severe PSTD symptoms should be conceived as high risk population requiring more attention.

Even thought, in comparison to general and clinical samples, high prevalence rates of PTSD among incarcerated populations have been more recognized and received more research interest, explicating the underlying risk factors and underpinnings of PTSD in these high risk groups requires further attention going beyond presence of or associations with early or prior traumatic experiences. Evidence has emerged in the literature was that prison inmates more frequently report remarkable levels of dissociative symptomatology concurrent with multi-traumas and more complicated clinical manifestation of posttraumatic stress responses (Akyuz et al., 2007; DeCou, Lynch, Cole, \& Kaplan, 2016; Salgado, Quinlan, \& Zlotnick, 2007; Steiner, Garcia, \& Matthews, 1997). On the other hand, there is growing evidence that sleep disruption associated with trauma exposure constitute a specific mechanism causally involved in the onset, maintenance and poor treatment outcomes of PTSD. The fear conditioning and extinction paradigms have been used to elaborate both animal and human models to unravel the role of sleep in PTSD. Fear conditioning, extinction and extinction recall can influence and in turn be influenced by REM sleep (Germain, 2013; Germain, Buysse, \& Nofzinger, 2008; Germain et al., 2011). Nevertheless, to date, the association between PTSD, dissociative symptomatology, posttraumatic cognitions, circadian preferences and sleep disturbances in terms of impaired sleep quality and insomnia has not been addressed among high risk populations, particularly among jail inmates. Based on the extant literature, the present study tested the hypothesis that the PTSD among incarcerated adults would likely to be far greater than general population. Second, we aimed to test whether individuals classified in a dissociative-PTSD subtype would exhibit more complicated clinical characteristics marked by more severe PTSD symptoms, greater sleep difficulties, higher scores on trauma-related negative cognitions, and more proneness to evening-type diurnal preferences than prisoners without pathological dissociation or PTSD. Third, we expected that individuals who reported greater levels of dissociative experiences, more severe sleep disturbances, higher levels of posttraumatic cognitions, and a tendency to eveningness diurnal preferences would be at higher risk for probable DSM-5 PTSD caseness.

\section{METHOD}

\section{Participants and Procedure}

The participants were recruited from adult prisoners in Van M Type Prison, Turkey. Prisoners who completed at least 1 month of their incarceration included in the study. Eight observations were discarded due to 
incomplete screening tools. The sample consisted of 399 adult prisoners, aged from 18 to 75 years. The average age of inmates was $34.54 \pm 9.93$ years. The vast majority of the prisoners were male $(n=389,97.5 \%) .60 .2 \%$ of the participants were married and $61.9 \%$ reported having at least one child. Almost half of the respondents were comprised of sentenced prisoners $(n=26,51.6 \%)$.

Considering clinical characteristics of the sample, $59.4 \%$ of prisoners were identified as DSM-5 PTSD caseness. Approximately all participants reported at least one type of prior trauma exposure as indexed by the LEC-5 ( $n=367,91.98 \%) .36 .8 \%$ had pathological levels of dissociation (DES $\geq 30$ ) and $31.6 \%$ were classified into DES-taxon membership according to the algorithm proposed by Waller, Putnam, and Carlson (1996). Although majority of the respondents consisted of morning- (42.9\%) and neither-type (52.6\%) individuals, $70.4 \%$ of incarcerated adults were poor sleepers and $37.8 \%$ had clinical insomnia. Findings are presented in Table 1.

The study was conducted from May 2017 through August 2017. The surveys were conducted in participants' personal rooms. The participants were informed about the aim and procedure of the study, and then self-

Table 1. Socio-demographic and clinical characteristics of participants

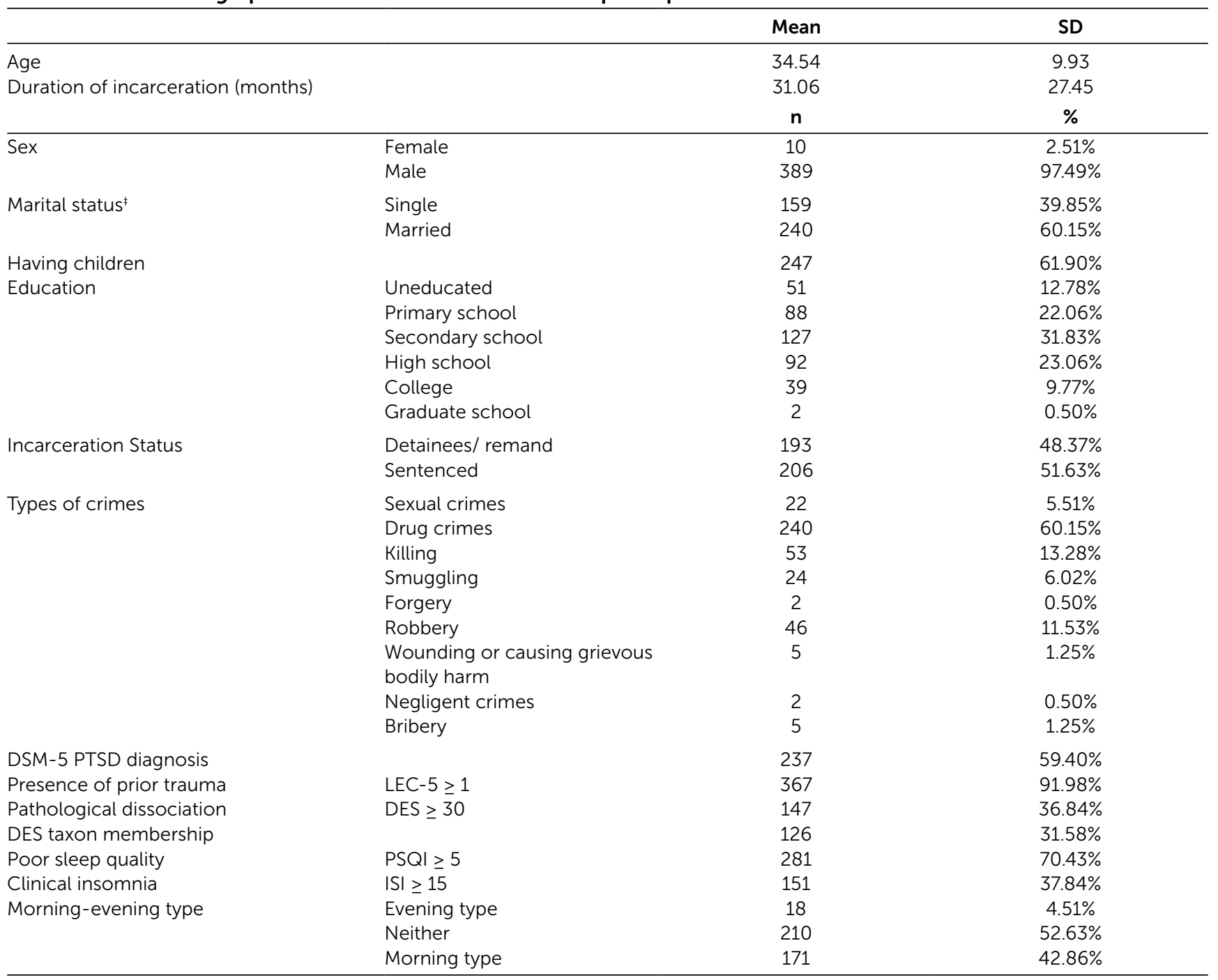

Note. ${ }^{\ddagger}$ Divorced $(n=15,3.76 \%)$ and widowed $(n=6,1.50 \%)$ participant are represented in single marital status. 67 participants (16.79\%) who were waiting supreme court are included in detainees group. LEC-5 = Life Event Checklist for DSM-5; DES = Dissociative Experiences Scale; PSQI = Pittsburgh Sleep Quality Index; ISI = Insomnia Severity Index 
reported questionnaires were administered to them with the assistance of trained psychologists.

The permission for this study was granted from the Republic of Turkey Ministry of Justice. The study protocol and procedures were approved by the Institutional Review Board of the Van Yüzüncü Yll University. Written informed consent was obtained from each participant. Participants were not compensated for their involvement in the study.

\section{Instruments}

\section{PTSD Checklist for DSM-5 (PCL-5)}

The PCL-5 (Blevins, Weathers, Davis, Witte, \& Domino, 2015) is a 20-item self-report measure designed to assess severity of DSM-5 PTSD symptoms. Respondents are asked to rate severity of each symptom from 0 (not at all) to 4 (extremely). There are three versions of the PCL-5: One version assesses symptoms of PTSD without Criterion $A$, the second one assesses PTSD symptoms including a brief Criterion $A$, and the third one includes the Life events Checklist for DSM-5 (LEC-5) with a Criterion A section. We administered the third version of the PCL-5 which includes the LEC-5. Turkish version of the instrument was demonstrated to have excellent psychometric properties, with high internal consistency $(a=0.94)$ and test-retest reliability $(r=0.80)$, as well as convergent validity (Boysan et al., 2017).

\section{Dissociative Experiences Scale (DES)}

The DES (Carlson \& Putnam, 1993) is a 28-item selfreport measure designed to screen dissociative experiences in community and clinical populations. Items are scored on a scale ranging from 0 ("not at all") to 100 ("almost every time"), and the summed up scores are averaging to yield an overall severity level in dissociative symptomatology. The Turkish version demonstrated good internal consistency $(a=0.97)$ and test-retest reliability $(r=0.77)$, as well as convergent validity (Yargic, Tutkun, \& Sar, 1995).

Posttraumatic Cognitions Inventory (PTCI)

The PTCI (Foa, Ehlers, Clark, Tolin, \& Orsillo, 1999) was developed to assess negative thoughts and beliefs of trauma exposed individuals. The screening tool contains 33 self-report items, yielding three subscales: negative cognitions about self (21 items), negative cognitions about the world (7 items) and self-blame for the trauma (5 items). Respondents are asked to rate each item on a 7-point Likert type scale, ranging from 1 ("totally disagree") to 7 ("totally agree"). The Turkish version of the scale was demonstrated to have excellent reliability and validity (Gulec, Kalafat, Boysan, \& Barut, 2013).

\section{Pittsburgh Sleep Quality Index (PSQI)}

The Pittsburgh Sleep Quality Index (PSQI) is a reliable and valid instrument assessing sleep quality and disturbances over a 1-month time interval (Buysse, Reynolds, Monk, Berman, \& Kupfer, 1989). The measure consists of 19 self-report questions. The PSQl yields seven components representing the dimensions of sleep quality: Subjective sleep quality, sleep latency, sleep duration, habitual sleep efficiency, sleep disturbances, use of sleeping medication, and daytime dysfunction. The Turkish version of the PSQI adapted by Agargun, Kara, and Anlar (1996). A cut score of PSQI $\geq 5$ discriminates well poor from good sleepers, and is an excellent general screening measure of sleep disturbances (Yildirim \& Boysan, 2017).

\section{Insomnia Severity Index (ISI)}

The ISI is a reliable and valid instrument designed to assess severity of $d$ insomnia. Participants are asked to rate 7 self-reported items relevant to severity of difficulties with sleep onset, sleep maintenance, earlymorning awakening, sleep problem interference with daily functioning, indications to others of impairment due to sleep problems, degree of concern about the current sleep problem, and satisfaction/dissatisfaction with current sleep pattern (Bastien, Vallieres, \& Morin, 2001). Each item is rated on a scale ranging from 0 to 4 and the scale yields scores ranging from 0 to 28. Higher scores are attributable to more severe insomnia. The Turkish version of the ISI revealed promising psychometric properties with an internal reliability of $a=0.79$ and two-week test-retest reliability of $r=0.82$ 
(Boysan, Gulec, Besiroglu, \& Kalafat, 2010).

\section{Morningness-Eveningness Questionnaire (MEQ)}

The MEQ (Horne \& Ostberg, 1975) is the most widely used tool to identify sleep chronotype preferences. The screening tool has 19 self-reported items and yields scores ranging from 16 to 86 . Participants who score between 59 and 86 are classified as morning-type, who score between 42 and 58 are classified as neither-type, and who score between 16 and 41 are classified as evening-type. The Turkish version of the MEQ was demonstrated to have good validity and reliability. Cronbach's alpha coefficient for 19 items was $r=0.81$ (Agargun et al., 2007).

\section{Data Analysis}

We commenced with performing descriptive statistics for clinical and socio-demographic characteristics of the prisoners. We classified participants into four groups including prisoners having a probable DSM-5 PTSD with (DES $\geq 30$ ) and without (DES< 30) pathological dissociation, and prisoners having no DSM-5 PTSD with and without pathological dissociation. Using one-way analysis of variance we compared differences in the mean scores on the subscales of the PCL-5, DES, PTCI, PSQl, as well as on the ISI and MEQ total across these four groups. Then, we run a multiple logistic regression analysis and a stepwise regression analysis separately, in which DSM-5 PTSD diagnosis was dependent variable in each model. In the multiple logistic regression model, total scale scores on the LEC-5, DES, PTCI, MEQ, ISI, and PSQI were regressed onto probable DSM-5 PTSD caseness after controlling for age, duration of incarceration, sex, marital status, having child, levels of education, and incarceration status. In the stepwise regression analysis, adhering to forward conditional procedure, we regressed subscales of the DES, PTCI, PSQI, as well as the total scores of the LEC-5, ISI, and MEQ onto DSM-5 PTSD caseness after controlling for socio-demographic variables (age, duration of incarceration, sex, marital status, having child, levels of education, and incarceration status). The statistical threshold was set at $p<0.05$.

\section{RESULTS}

The mean PCL-5 total score was 37.70 ( \pm 20.65$)$. Based on DSM-5 criteria for PTSD diagnosis including at least one re-experiencing symptom, one avoidance symptom, two negative alterations in cognitions and mood, and two hyper-arousal symptoms of at least moderate severity (2 or higher) DSM-5 PTSD caseness in the sample was determined. Accordingly, 59.4\% of the respondents were allocated in probable DSM-5 PTSD sub-group. Based on the DES total scores, we also splitted the sample into two subgroups: high dissociators (DES $\geq 30$ ) and low dissociators (DES< 30).

When we cross tabulated prisoners with and without probable DSM-5 PTSD and those prisoners with and without pathological dissociation, we obtained four subgroups: dissociative PTSD, pure PTSD, pure dissociators, and no PTSD or dissociation. 115 cases were classified into dissociative PTSD subgroup (28.82\%), 112 cases had pure PTSD (30.58\%), 32 prisoners were pure dissociators (8.02\%), and 130 had neither PTSD nor pathological dissociation (32.58\%). We run one-way analysis of variance across these four subgroups to investigate differences in the mean scale scores on the PCL-5, LEC-5, DES, PTCI, MEQ, ISI, and PSQI. The post hoc comparisons were conducted using Bonferroni multiple group comparison test.

As can be seen in Table 2, dissociative PTSD group reported significantly greater scores on the PCL-5 total and four subscales of the PCL-5 (intrusions, negative alterations in cognitions and mood, hyper-arousal) than other three groups (pure PTSD, pure dissociators, and no PTSD or dissociation). Irrespective of dissociative tendency, prison inmates with probable DSM-5 PTSD reported higher scores on the avoidance subscale of the PCL-5 than did prisoners without PTSD. We observed that pure dissociators had the lowest scores on prior traumatic experiences as indexed by the LEC- 5 which was statistically significantly differentiated from the dissociative PTSD group with highest trauma exposure scores. High dissociators reported significantly higher scores on the total and subscales of the DES compared to 


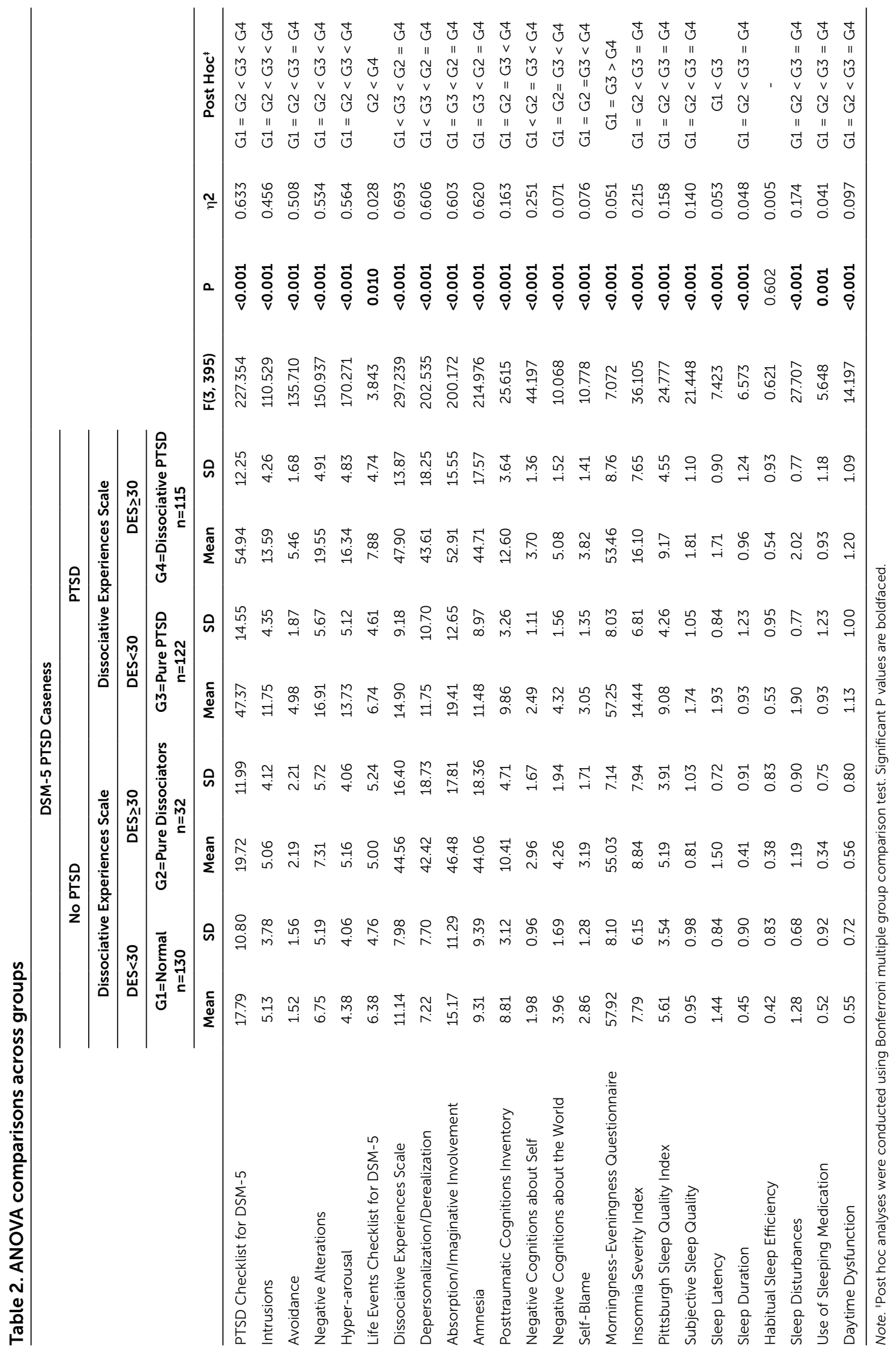


low dissociators. In comparison to other three groups, high dissociators with PTSD had statistically significantly higher scores on total and subscale scores of the PTCI. Individuals classified in dissociative PTSD subgroup were more prone to have eveningness diurnal preferences. Prisoners with probable DSM-5 PTSD had significantly worst sleep quality than prisoners without PTSD whether they had pathological dissociation or not.

Using multiple logistic modeling approach, after controlling for socio-demographic variables (age, duration of incarceration, incarceration status, sex, marital status, having child, and levels of education), total scores on the LEC-5, DES, PTCI, MEQ, ISI, and PSQI were regressed onto binary dependent variable (probable DSM-5 PTSD caseness vs no PTSD). The multiple logistic regression analysis showed that being male $(O R=9.192, p=0.042,95 \%$ confidence interval $=$
1.084-77.923), the DES (OR $=1.038, p<0.001,95 \%$ confidence interval $=1.022-1.055)$, the ISI $(O R=1.120$, $p<0.001,95 \%$ confidence interval $=1.071-1.170)$, and the PSQI $(O R=1.151, p<0.001,95 \%$ confidence interval $=1.071-1.237)$ scores significantly contributed to the development of PTSD among prisoners. Findings are presented in Table 3.

Next, we run a stepwise logistic regression analysis using forward conditional method in which probable DSM-5 PTSD caseness was the dependent variable. Socio-demographic variables (age, duration of incarceration, incarceration status, sex, marital status, having child, and education level), the LEC-5, MEQ, ISI total scores, as well as depersonalization / derealization, absorption / imaginative involvement, amnesia subscale scores of the DES, negative cognitions about self, negative cognitions about the world and self-blame subscale

Table 3. Logistic regression analysis on DSM-5 PTSD caseness

\begin{tabular}{lccc}
\hline & Odds Ratio & P & $\mathbf{9 5 , 0 \%}$ C.I. \\
\hline Age & 0.985 & 0.373 & $0.953-1.018$ \\
Duration of Incarceration & 0.996 & 0.479 & $0.986-1.007$ \\
Sex & 9.192 & $\mathbf{0 . 0 4 2}$ & $1.084-77.923$ \\
Marital status & 1.629 & 0.278 & $0.675-3.934$ \\
Having child & 0.775 & 0.587 & $0.309-1.943$ \\
Education & 1.024 & 0.828 & $0.824-1.273$ \\
Incarceration Status & 1.634 & 0.095 & $0.919-2.905$ \\
Life Events Checklist for DSM-5 & 1.037 & 0.177 & $0.984-1.093$ \\
Dissociative Experiences Scale & 1.038 & $<\mathbf{0 . 0 1}$ & $1.022-1.055$ \\
Posttraumatic Cognitions Inventory & 1.047 & 0.225 & $0.972-1.126$ \\
Morningness-Eveningness Questionnaire & 1.029 & 0.090 & $0.996-1.064$ \\
Insomnia Severity Index & 1.120 & $<\mathbf{0 . 0 0 1}$ & $1.071-1.170$ \\
Pittsburgh Sleep Quality Index & 1.151 & $<\mathbf{0 . 0 0 1}$ & $1.071-1.237$
\end{tabular}

Note. Significant $P$ values are boldfaced.

Table 4. Stepwise logistic regression on DSM-5 PTSD caseness

\begin{tabular}{|c|c|c|c|c|}
\hline & Nagelkerke's $\mathrm{R}^{2}$ & Odds Ratio & $\mathbf{P}$ & 95\% C.I. \\
\hline STEP 1 & 0.278 & & & \\
\hline Insomnia Severity Index & & 1.158 & $<0.001$ & $1.119-1.199$ \\
\hline STEP 2 & 0.350 & & & \\
\hline Insomnia Severity Index & & 1.124 & $<0.001$ & $1.085-1.166$ \\
\hline Sleep Disturbances & & 2.309 & $<0.001$ & $1.676-3.180$ \\
\hline STEP 3 & 0.402 & & & \\
\hline Absorption/Imaginative Involvement & & 1.030 & $<0.001$ & $1.017-1.044$ \\
\hline Insomnia Severity Index & & 1.118 & $<0.001$ & $1.077-1.161$ \\
\hline Sleep Disturbances & & 2.130 & $<0.001$ & $1.535-2.956$ \\
\hline STEP 4 & 0.411 & & & \\
\hline Sex & & 9.005 & 0.033 & $1.197-67.736$ \\
\hline Absorption/Imaginative Involvement & & 1.033 & $<0.001$ & $1.019-1.048$ \\
\hline Insomnia Severity Index & & 1.124 & $<0.001$ & $1.081-1.168$ \\
\hline Sleep Disturbances & & 2.143 & $<0.001$ & $1.540-2.981$ \\
\hline
\end{tabular}


scores on the PTCl, and seven components of the PSQI were independent variables. The hierarchical logistic stepwise regression model converged at the fourth step. In the final step we observed that being male (OR = 9.005, $p=0.033,95 \%$ confidence interval $=1.197-67.736$ ), the ISI (OR $=1.124, p<0.001,95 \%$ confidence interval = 1.081-1.168), and the sleep disturbances component of the $\mathrm{PSO}(\mathrm{OR}=2.143, p<0.001,95 \%$ confidence interval $=$ 1.540-2.981), and absorption / imaginative involvement subscale of the DES (OR $=1.033, p<0.001,95 \%$ confidence interval $=1.019-1.048$ ) statistically significantly contributed to development of PTSD in adult prisoners. These four independent variables accounted for $41 \%$ of the unique variance of dependent variable. Results are reported in Table 4.

\section{DISCUSSION}

Trauma exposure is increasingly being recognized as a crucial risk factor emphasized in mental health models of criminal justice system. High prevalence rates of individuals with PTSD in relation to trauma exposure among incarcerated populations and its significant relations with co-occurrence of other psychiatric disorders, particularly substance use disorder and recidivism highlight the importance to understand underpinning factors conferring risk for development and maintenance of the PSTD in criminal justice system (Choe et al., 2008; Constantine et al., 2010; Scott, McGilloway, Dempster, Browne, \& Donnelly, 2013). The present study investigated the relations of DSM-5 PTSD caseness with prior trauma exposure, dissociation, posttraumatic cognitions, circadian preferences and sleep disturbances. We found that $59.4 \%$ screened positive for DSM-5 PTSD as measured by PCL-5 with a high prevalence of at least one type of reported prior trauma exposure (92.0\%), 36.8\% had pathological levels of dissociation, $70.4 \%$ had poor sleep quality, and $37.8 \%$ had clinical level of insomnia. The high rates of probable DSM-5 PTSD caseness and multiple trauma exposure, as well as significant relations with dissociative symptomatology were comparable with the previous studies (Akyuz et al., 2007; Briere et al., 2016; Cusack et al., 2013; DeCou et al., 2016; Henrichs \& Bogaerts, 2012; Karatzias et al., 2017; Sindicich et al., 2014; Steiner et al., 1997).

We used pathological DES scores $(\geq 30)$ to detect dissociative PTSD cases among prison inmates and found a sizable minority of the respondents were classified as having dissociative PTSD $(28.8 \%, n=115)$, the proportion of high dissociators with PTSD which was comparable to most of previous studies using taxometric models to detect dissociative-PTSD cases (Hansen et al., 2017; Lanius, Brand, Vermetten, Frewen, \& Spiegel, 2012). In keeping with the previous findings observed for individuals with dissociative PTSD (Ginzburg et al., 2006; Hansen et al., 2017; Lanius et al., 2012; Steuwe et al., 2012; Wolf, Lunney, et al., 2012), in the current data, members of dissociative PTSD group reported significantly greater number of average prior trauma exposure relative to pure PTSD, pure dissociators, or non-symptomatic baseline group.

The results of relatively sparse number of studies concerning the discrepancies between subtypes of PTSD have consistently pointed out that individuals with dissociative-PTSD revealed a more complicated clinical expression of the disorder: greater comorbidity (Steuwe et al., 2012; Wolf, Lunney, et al., 2012), a tendency to cope emotionally (Hansen, Mullerova, Elklit, \& Armour, 2016), more severe substance use problems (Mergler et al., 2017; Tsai, Armour, Southwick, \& Pietrzak, 2015), greater suicidality (Lanius et al., 2012; Lanius et al., 2014; McFarlane, 2013; Stein et al., 2013), memory and attention deficits (Roca, Hart, Kimbrell, \& Freeman, 2006; J. Ross, Banik, Dedova, Mikulaskova, \& Armour, 2017), more severe depressive and anxious symptomatology, greater risk for hostility and sleeping difficulties (Armour, Elklit, et al., 2014). In an attempt to add prior work we evaluated whether individuals with dissociative-PTSD significantly differed in sleep quality, insomnia, circadian preferences and posttraumatic cognitions compared to individuals with pure PTSD, pure dissociation or without traumainduced stress reactions. We hypothesized that these factors may be pertinent given the previously noted associations between PTSD and sleep (Casement \& Swanson, 2012; Ho, Chan, \& Tang, 2016; Khachatryan, 
Groll, Booij, Sepehry, \& Schutz, 2016; Nappi, Drummond, \& Hall, 2012) dissociation and sleep (Selvi et al., 2017; Van Der Kloet et al., 2013; van der Kloet, Giesbrecht, Lynn, Merckelbach, \& de Zutter, 2012; van der Kloet, Merckelbach, Giesbrecht, \& Lynn, 2012; van Heugten-van der Kloet, Giesbrecht, \& Merckelbach, 2015; van Heugten-van der Kloet, Huntjens, Giesbrecht, \& Merckelbach, 2014; van Heugten-van der Kloet, Merckelbach, et al., 2014), trauma-related stress responses and posttraumatic cognitions (Diehle, Schmitt, Daams, Boer, \& Lindauer, 2014; Swopes, Davis, \& Scholl, 2017; Woud, Verwoerd, \& Krans, 2017). Previous PTSD literature has suggested significant relationships between PTSD, dissociation, posttraumatic cognitions, sleep quality, insomnia and circadian preferences.

Keeping with the previous compelling evidence, results showed that those of individuals with dissociative PTSD reported the most severe levels of posttraumatic response symptoms, with the highest scores on intrusions, negative alternations on mood and cognition and arousal and startle responses as indexed by the PCL-5 relative to pure PTSD, pure dissociators and normal groups. As expected, jail inmates with dissociative PSTD were statistically distinguishable from other three groups with pronounced levels of posttraumatic cognitions scores on the PTCl total and sub-scales of negative cognitions about self and the world, and a tendency to self-blame. Turning to the sleep related variables, we observed that dissociative PTSD cases were more prone to eveningtype circadian preferences than individuals classified in other three subgroups. Participants with probable DSM5 PTSD, whether they had pathological levels of dissociation or not, reported significantly worse sleep quality and more severe insomnia compared to prisoners without PTSD. These findings confirmed and extended the extant research on discrepancies between dissociative and non-dissociative PTSD subtypes (Armour, Elklit, et al., 2014; Hansen et al., 2017; van Huijstee \& Vermetten, 2017).

Using logistic regression analysis, we found that dissociative symptomatology, insomnia severity and poor sleep quality significantly contributed to the unique variance of probable DSM-5 PTSD caseness after controlling for socio-demographic variables (age, duration of incarceration, sex, marital status, having child, level of education, incarceration status and number of trauma exposure prior to incarceration). When considering for the sub-scales of the DES, PTCl, and PSQI, as well as the MEQ and ISI after controlling for the demographic covariates, we found that absorption/ imaginative involvement as indexed by the DES, sleep disturbances component of the PSQI, and insomnia severity were significant antecedents of the heightened posttraumatic stress reactions in justice-involved criminal adults.

Given the high rates of clinically significant PTSD cases among jail inmates with a greater dissociative tendency and disproportionally greater risk for development of PSTD for incarcerated adults with sleep disturbances, healthcare providers should be aware of the high risk of trauma and stressor-related disorders in relation to sleep problems in correctional units. Providing psychiatric screening at the time of imprisonment and follow-up assessments with certain time intervals may facilitate detecting probable PSTD caseness and psychiatric comorbidities among these risky populations and referral to mental health resources and appropriate treatment plans. Continuity of health care programs for inmates afflicted with psychiatric conditions may be implemented to more accurately meet the mental health care among prisoners (Baillargeon, Binswanger, Penn, Williams, \& Murray, 2009). Treatment plans for PTSD concurrent with dissociative symptomatology targeting sleep disruptions can help to improve symptoms of trauma- or stress- induced psychological responses and other psychiatric conditions, as well as general health and psychological well-being in correctional units.

Several drawbacks should be considered when interpreting the present findings. First, this investigation was a cross-sectional study. Further explorations with longitudinal research design are needed to expand our understanding of the role of interactions between dissociative symptomatology and sleep disturbances in the onset and perseverance of PTSD in prisoners. Second, the study was conducted in a correlation institution among a relatively small sample of jail inmates 
and the number of women was excessively small that may limit the generalizability of the results and may lack adequate power to identify significant discrepancies. Third, self-report measures of psychiatric conditions and related psychological constructs were utilized instead of clinician interviews. Similarly, objective measures of sleep such a polysomnography could have provided more reliable and profound assessments relative to subjective measurement procedures as adopted in the present study. Forth, although objective diagnostic data emerged in polysomnography studies indicate widely varying prevalence rates, more recent studies have provided compelling evidence that increased frequency of sleepdisordered breathing in PTSD patients (Krakow, Ulibarri, Moore, \& Mclver, 2015). Nevertheless, in the present data, we did not address sleep-disordered breathing in relation to PTSD. Finally, the fact that comorbid PTSD and substance use disorders are common in jail inmates and linked to a more complicated expression of the trauma-related symptomatology, and behavioral inhibition disturbances, particularly relevant to recidivism (N. Messina, Burdon, Hagopian, \& Prendergast, 2004; Salgado et al., 2007; Sindicich et al., 2014; Wallace et al., 1998; Wolff, Frueh, Shi, \& Schumann, 2012; Wolff \& Shi, 2011). However, we did not make an assessment concerning history of substance use disorder in the current investigation.

\section{CONCLUDING COMMENTS}

The robust evidence emerged in review of the literature was that the frequency of traumatic experiences preceding incarceration far exceeds the respective prevalence rates in general population, and it seems, despite unconfirmed in the present data, prior trauma exposure pose significant risk for development of PTSD as well as other psychiatric morbidities which are tentatively mediated by posttraumatic symptoms in prison population (Greene, Ford, Wakefield, \& Barry, 2014). Untreated PTSD may further complicate the clinical picture of other psychiatric disorders particularly among women inmates, thereby compromising the efficiency of psychological and psychopharmacological interventions (Kubiak, 2004). Presence of severe posttraumatic symptomatology appears to be significantly affecting interpersonal relationships, regulation of affect, arousal and impulsivity during conviction and post-incarceration that results in increased rates of aggressive and violent behaviours and substance use disorders, which in turn are substantially associated with recidivism (Asberg \& Renk, 2012; Ford, Chapman, Mack, \& Pearson, 2006; Ford, Grasso, Hawke, \& Chapman, 2013; N. Messina et al., 2004; Sindicich et al., 2014). On the other hand, successful interventions targeting PTSD symptomatology were identified to be associated with resolution of victimization and significant improvement in substance use and recidivism (Ford, Chang, Levine, \& Zhang, 2013; N. Messina \& Calhoun, 2014; Zlotnick, Johnson, \& Najavits, 2009). Early prevention and intervention programs might help alleviate burden of physical and mental health problems experienced by offenders with a history of trauma (Gosein et al., 2016; Green et al., 2016; Green, Miranda, Daroowalla, \& Siddique, 2005; Maschi, Morgen, Zgoba, Courtney, \& Ristow, 2011; N. Messina \& Grella, 2006; N. Messina, Grella, Burdon, \& Prendergast, 2007; N. P. Messina, Burdon, \& Prendergast, 2003).

The role of sleep in the development and maintenance of PTSD appears to be complex, but sleep studies in PTSD is an important avenue for understanding the nature and treatment of the disorder. The premise that that sleep disturbances in the aftermath following adverse life events contribute to poor psychological outcomes may facilitate the provision of management strategies aim to enhance resilience and recovery in PTSD. Cognitive-behavioral interventions targeting posttraumatic nightmares and insomnia contribute to very significant improvement in sleep and daytime PTSD symptom severity (Davis, 2008; Germain, Shear, Hall, \& Buysse, 2007; Krakow \& Zadra, 2010). In a related vein, cognitive behavioral interventions and psycho-education programs resulted in comparable improvement in PTSD severity were significantly associated with improvement in sleep symptoms (McHugh et al., 2014). Furthermore, continuous positive airway pressure treatment in PTSD patients with sleep-disordered breathing reduces sleep 
fragmentation and psycho-physiological arousal (Krakow, Melendrez, Warner, et al., 2002). Psychopharmacological and behavioral treatments targeting sleep disturbance in PTSD have demonstrated to be beneficial to improvements in nightmares and insomnia, which are often more resistant relative to subjective complaints of sleep in PTSD, concomitant with severity of daytime PTSD symptoms and other stress-related psychiatric comorbidities (Germain, 2013). This study provided further evidence supporting the pivoting role of sleep disturbances, particularly poor sleep quality and insomnia along with pathological dissociation in PTSD. The current findings suggested that incorporation of sleep-related interventions targeting nightmares and insomnia may provide significant improvement in the clinical outcomes of trauma-informed treatment approaches for prisoners with PTSD.

\section{References}

Agargun, M. Y., Cilli, A. S., Boysan, M., Selvi, Y., Gulec, M., \& Kara, H. (2007). Turkish version of Morningness- Eveningness Questionnaire (MEQ). Sleep and Hypnosis, 9(1), 16-23.

Agargun, M. Y., Kara, H., \& Anlar, Ö. (1996). Validity and reliability of the Pittsburgh Sleep Quality Index. Turkish Journal of Psychiatry, 7(2), 107-115.

Agargun, M. Y., Kara, H., Ozer, O. A., Selvi, Y., Kiran, U., \& Kiran, S. (2003). Nightmares and dissociative experiences: The key role of childhood traumatic events. Psychiatry and Clinical Neuroscience, 57(2), 139-145. doi:10.1046/j.1440-1819.2003.01093.x

Agargun, M. Y., Kara, H., Ozer, O. A., Selvi, Y., Kiran, U., \& Ozer, B. (2003). Clinical importance of nightmare disorder in patients with dissociative disorders. Psychiatry and Clinical Neuroscience, 57(6), 575-579. doi:10.1046/j.1440-1819.2003.01169.x

Akyuz, G., Kugu, N., Sar, V., \& Dogan, O. (2007). Trauma and dissociation among prisoners. Nordic Journal of Psychiatry, 61(3), 167-172. doi:10.1080/08039480701352348

American Psychiatric Association. (2013). Diagnostic and Statistical Manual of Mental Disorders, 5th Edition: DSM-5. Washington, DC: American Psychiatric Publishing.

Anderson, R. E., Geier, T. J., \& Cahill, S. P. (2016). Epidemiological associations between posttraumatic stress disorder and incarceration in the National Survey of American Life. Criminal Behaviour and Mental Health, 26(2), 110-123. doi:10.1002/ cbm.1951

Ardino, V. (2012). Offending behaviour: The role of trauma and PTSD. European Journal of Psychotraumatology, 3. doi:10.3402/ejpt.v3i0.18968

Armour, C., Contractor, A. A., Palmieri, P. A., \& Elhai, J. D. (2014). Assessing latent level associations between PTSD and dissociative factors: Is depersonalization and derealization related to PTSD factors more so than alternative dissociative factors? Psychological Injury and Law, 7(2), 131-142. doi:10.1007/s12207-014-9196-9
Acknowledgements: None declared.

Funding: The authors declare that the current study was not financially supported by any institution or organization.

Ethical approval: All procedures performed in studies involving human participants were in accordance with the ethical standards of the institutional and/or national research committee and with the 1964 Helsinki declaration and its later amendments or comparable ethical standards.

Informed consent: Informed consent was obtained from all individual participants included in the study.

Conflict of interest: The authors declare no conflict of interest.

Author declaration: The paper used the data set from the first author's dissertation, expertly advised by the third author.

Armour, C., Elklit, A., Lauterbach, D., \& Elhai, J. D. (2014). The DSM-5 dissociative-PTSD subtype: Can levels of depression, anxiety, hostility, and sleeping difficulties differentiate between dissociative-PTSD and PTSD in rape and sexual assault victims? Journal of Anxiety Disorders, 28(4), 418-426. doi:10.1016/j. janxdis.2013.12.008

Armour, C., Karstoft, K. I., \& Richardson, J. D. (2014). The cooccurrence of PTSD and dissociation: differentiating severe PTSD from dissociative-PTSD. Social Psychiatry and Psychiatric Epidemiology, 49(8), 1297-1306. doi:10.1007/s00127-0140819-y

Asberg, K., \& Renk, K. (2012). Substance use coping as a mediator of the relationship between trauma symptoms and substance use consequences among incarcerated females with childhood sexual abuse histories. Substance Use and Misuse, 47(7), 799-808. doi:10.3109/10826084.2012.669446

Babson, K. A., Boden, M. T., Woodward, S., Alvarez, J., \& BonnMiller, M. (2013). Anxiety sensitivity and sleep quality: independent and interactive predictors of posttraumatic stress disorder symptoms. Journal of Nervous and Mental Disease, 201(1), 48-51. doi:10.1097/NMD.0b013e31827ab059

Baillargeon, J., Binswanger, I. A., Penn, J. V., Williams, B. A., \& Murray, O. J. (2009). Psychiatric disorders and repeat incarcerations: The revolving prison door. American Journal of Psychiatry, 166(1), 103-109. doi:10.1176/appi.ajp.2008.08030416

Bastien, C. H., Vallieres, A., \& Morin, C. M. (2001). Validation of the Insomnia Severity Index as an outcome measure for insomnia research. Sleep Medicine, 2(4), 297-307. doi:10.1016/S13899457(00)00065-4

Betts, K. S., Williams, G. M., Najman, J. M., \& Alati, R. (2013). The role of sleep disturbance in the relationship between posttraumatic stress disorder and suicidal ideation. Journal of Anxiety Disorders, 27(7), 735-741. doi:10.1016/j. janxdis.2013.09.011 
Blevins, C. A., Weathers, F. W., Davis, M. T., Witte, T. K., \& Domino, J. L. (2015). The Posttraumatic Stress Disorder Checklist for DSM-5 (PCL-5): Development and initial psychometric evaluation. Journal of Traumatic Stress, 28(6), 489-498. doi:10.1002/jts.22059

Blevins, C. A., Weathers, F. W., \& Witte, T. K. (2014). Dissociation and posttraumatic stress disorder: A latent profile analysis. Journal of Traumatic Stress, 27(4), 388-396. doi:10.1002/ jts.21933

Blonigen, D. M., Sullivan, E. A., Hicks, B. M., \& Patrick, C. J. (2012). Facets of psychopathy in relation to potentially traumatic events and posttraumatic stress disorder among female prisoners: The mediating role of borderline personality disorder traits. Personality Disorders-Theory Research and Treatment, 3(4), 406-414. doi:10.1037/a0026184

Boysan, M. (2014). Dissociative experiences are associated with obsessive-compulsive symptoms in a non-clinical sample: A latent profile analysis. Archives of Neuropsychiatry, 51(3), 253262. doi:10.4274/npa.y6884

Boysan, M. (2016). Associations between dissociation and posttraumatic stress response. In C. R. Martin, V. R. Preedy, \& V. B. Patel (Eds.), Comprehensive guide to post-traumatic stress disorder (pp. 831-849). New York, NY: Springer.

Boysan, M., Gulec, M., Besiroglu, L., \& Kalafat, T. (2010). Psychometric properties of the Insomnia Severity Index in Turkish sample. Anadolu Psikiyatri Dergisi-Anatolian Journal of Psychiatry, 11(3), 248-252.

Boysan, M., Ozdemir, P. G., Ozdemir, O., Selvi, Y., Yilmaz, E., \& Kaya, N. (2017). Psychometric properties of the Turkish version of the PTSD Checklist for Diagnostic and Statistical Manual of Mental Disorders, Fifth Edition (PCL-5). Psychiatry and Clinical Psychopharmacology, 27(3), 306-316. doi:10.1080/24750573. 2017.1342769

Boysan, M., Yildirim, A., Besiroglu, L., Kefeli, M. C., \& Kagan, M. (2018). Development and preliminary psychometric properties of an instrument for the measurement of obsessional dissociative experiences: The Van Obsessional Dissociation Questionnaire (VOD-Q). Psychiatric Quarterly. doi:10.1007/ s11126-017-9555-2

Breslau, N., Roth, T., Burduvali, E., Kapke, A., Schultz, L., \& Roehrs, T. (2004). Sleep in lifetime posttraumatic stress disorder: a community-based polysomnographic study. Archives of General Psychiatry, 61(5), 508-516. doi:10.1001/ archpsyc.61.5.508

Breslau, N., Roth, T., Rosenthal, L., \& Andreski, P. (1996). Sleep disturbance and psychiatric disorders: a longitudinal epidemiological study of young adults. Biological Psychiatry, 39(6), 411-418.

Briere, J., Agee, E., \& Dietrich, A. (2016). Cumulative trauma and current posttraumatic stress disorder status in general population and inmate samples. Psychological Trauma-Theory Research Practice and Policy, 8(4), 439-446. doi:10.1037/ tra0000107

Browne, A., Miller, B., \& Maguin, E. (1999). Prevalence and severity of lifetime physical and sexual victimization among incarcerated women. International Journal of Law and Psychiatry, 22(3-4), 301-322. doi:Doi 10.1016/S01602527(99)00011-4

Bryant, R. A. (2005). Predicting posttraumatic stress disorder from acute reactions. Journal of Trauma and Dissociation, 6(2), 5-15. doi:10.1300/J229v06n02_02

Bryant, R. A., Creamer, M., O’Donnell, M., Silove, D., \& McFarlane, A. C. (2010). Sleep disturbance immediately prior to trauma predicts subsequent psychiatric disorder. Sleep, 33(1), 69-74.
Bryant, R. A., Harvey, A. G., Guthrie, R. M., \& Moulds, M. L. (2000). A prospective study of psychophysiological arousal, acute stress disorder, and posttraumatic stress disorder. Journal of Abnormal Psychology, 109(2), 341-344.

Butler, L. D., Duran, R. E., Jasiukaitis, P., Koopman, C., \& Spiegel, D. (1996). Hypnotizability and traumatic experience: A diathesisstress model of dissociative symptomatology. American Journal of Pyschiatry, 153 (7 Suppl), 42-63. doi:10.1176/ ajp.153.8.A42

Buysse, D. J., Reynolds, C. F., Monk, T. H., Berman, S. R., \& Kupfer, D. J. (1989). The Pittsburgh Sleep Quality Index: A new instrument for psychiatric practice and research. Psychiatry Research, 28(2), 193-213. doi:Doi 10.1016/01651781(89)90047-4

Carlson, E. B., \& Putnam, F. W. (1993). An update on the Dissociative Experiences Scale. Dissociation, 6, 16-27.

Casement, M. D., \& Swanson, L. M. (2012). A meta-analysis of imagery rehearsal for post-trauma nightmares: Effects on nightmare frequency, sleep quality, and posttraumatic stress. Clinical Psychology Review, 32(6), 566-574. doi:10.1016/j. cpr.2012.06.002

Cheung, V. K. L. (2012). An exploratory study on the relationship between dissociation in waking life and negative contents in dreams. International Journal of Dream Research, 5(1), 17-22.

Choe, J. Y., Teplin, L. A., \& Abram, K. M. (2008). Perpetration of violence, violent victimization, and severe mental illness: Balancing public health concerns. Psychiatric Services, 59(2), 153-164. doi:DOI 10.1176/appi.ps.59.2.153

Clum, G. A., Nishith, P., \& Resick, P. A. (2001). Trauma-related sleep disturbance and self-reported physical health symptoms in treatment-seeking female rape victims. Journal of Nervous and Mental Disease, 189(9), 618-622.

Collins, J. J., \& Bailey, S. L. (1990). Traumatic stress disorder and violent behavior. Journal of Traumatic Stress, 3, 203-220. doi:10.1007/BF00975146

Constantine, R. J., Petrila, J., Andel, R., Givens, E. M., Becker, M., Robst, J., . . Howe, A. (2010). Arrest trajectories of adult offenders with a serious mental illness. Psychology Public Policy and Law, 16(4), 319-339. doi:10.1037/a0020852

Cusack, K. J., Herring, A. H., \& Steadman, H. J. (2013). PTSD as a mediator between lifetime sexual abuse and substance use among jail diversion participants. Psychiatric Services, 64(8), 776-781. doi:10.1176/appi.ps.000052012

Davis, J. L. (2008). Treating post-trauma nightmares: A cognitive behavioral approach. New York, NY: Springer.

DeCou, C. R., Lynch, S. M., Cole, T. T., \& Kaplan, S. P. (2016). Dissociation mediates the association between intimate partner violence and posttraumatic stress among treatment-seeking incarcerated women. Journal of Trauma \& Dissociation, 17(4), 480-493. doi:10.1080/15299732.2016.1141148

Dell'Osso, L., Armani, A., Rucci, P., Frank, E., Fagiolini, A., Corretti, G., ... Cassano, G. B. (2002). Measuring mood spectrum: comparison of interview (SCl-MOODS) and self-report (MOODS-SR) instruments. Comprehensive Psychiatry, 43(1), 69-73.

Dell'Osso, L., Massimetti, G., Conversano, C., Bertelloni, C. A., Carta, M. G., Ricca, V., \& Carmassi, C. (2014). Alterations in circadian/seasonal rhythms and vegetative functions are related to suicidality in DSM-5 PTSD. BMC Psychiatry, 14, 352 doi:10.1186/s12888-014-0352-2

Diehle, J., Schmitt, K., Daams, J. G., Boer, F., \& Lindauer, R. J. L. (2014). Effects of psychotherapy on trauma-related cognitions in posttraumatic stress disorder: A meta-analysis. Journal of Traumatic Stress, 27(3), 257-264. doi:10.1002/jts.21924 
Donley, S., Habib, L., Jovanovic, T., Kamkwalala, A., Evces, M., Egan, G., . . Ressler, K. J. (2012). Civilian PTSD symptoms and risk for involvement in the criminal justice system. Journal of the American Academy of Psychiatry and the Law, 40(4), 522-529.

Dudeck, M., Drenkhahn, K., Spitzer, C., Barnow, S., Kopp, D., Kuwert, P., . . . Dunkel, F. (2011). Traumatization and mental distress in long-term prisoners in Europe. Punishment $\&$ Society-International Journal of Penology, 13(4), 403-423. doi:10.1177/1462474511414782

Ebdlahad, S., Nofzinger, E. A., James, J. A., Buysse, D. J., Price, J. C., \& Germain, A. (2013). Comparing neural correlates of REM sleep in posttraumatic stress disorder and depression: a neuroimaging study. Psychiatry Research, 214(3), 422-428. doi:10.1016/j.pscychresns.2013.09.007

Flatt, J. D., Williams, B. A., Barnes, D., Goldenson, J., \& Ahalt, C. (2017). Post-traumatic stress disorder symptoms and associated health and social vulnerabilities in older jail inmates. Aging \& Mental Health, 21(10), 1106-1112. doi:10.1080/136078 63.2016.1201042

Foa, E. B., Ehlers, A., Clark, D. M., Tolin, D. F., \& Orsillo, S. M. (1999). The Posttraumatic Cognitions Inventory (PTCl): Development and validation. Psychological Assessment, 11(3), 303-314. doi:Doi 10.1037/1040-3590.11.3.303

Ford, J. D., Chang, R., Levine, J., \& Zhang, W. L. (2013). Randomized clinical trial comparing affect regulation and supportive group therapies for victimization-related PTSD with incarcerated women. Behavior Therapy, 44(2), 262-276. doi:10.1016/j. beth.2012.10.003

Ford, J. D., Chapman, J., Mack, M., \& Pearson, G. (2006). Pathway from traumatic child victimization to delinquency: Implications for juvenile and permanency court proceedings and decisions. Juvenile and Family Court Journal, 57(1), 13-26. doi:DOI 10.1111/j.1755-6988.2006.tb00111.x

Ford, J. D., Grasso, D. J., Hawke, J., \& Chapman, J. F. (2013). Polyvictimization among juvenile justice-involved youths. Child Abuse and Neglect, 37(10), 788-800. doi:10.1016/j. chiabu.2013.01.005

Frewen, P. A., Brown, M. F. D., Steuwe, C., \& Lanius, R. A. (2015). Latent profile analysis and principal axis factoring of the DSM-5 dissociative subtype. European Journal of Psychotraumatology, 6. doi:10.3402/ejpt.v6.26406

Germain, A. (2013). Sleep disturbances as the hallmark of PTSD: Where are we now? American Journal of Psychiatry, 170(4), 372-382. doi:10.1176/appi.ajp.2012.12040432

Germain, A., Buysse, D. J., \& Nofzinger, E. (2008). Sleep-specific mechanisms underlying posttraumatic stress disorder: Integrative review and neurobiological hypotheses. Sleep Medicine Reviews, 12(3), 185-195. doi:10.1016/j.smrv.2007.09.003

Germain, A., Buysse, D. J., Shear, M. K., Fayyad, R., \& Austin, C. (2004). Clinical correlates of poor sleep quality in posttraumatic stress disorder. Journal of Traumatic Stress, 17(6), 477-484. doi:10.1007/s10960-004-5796-6

Germain, A., Hall, M., Krakow, B., Katherine Shear, M., \& Buysse, D. J. (2005). A brief sleep scale for Posttraumatic Stress Disorder: Pittsburgh Sleep Quality Index Addendum for PTSD. Journal of Anxiety Disorders, 19(2), 233-244. doi:10.1016/j. janxdis.2004.02.001

Germain, A., Mammen, O., Price, P., \& Nofzinger, E. A. (2011). Functional neuroimaging of REM sleep in returning veterans with PTSD: An [18F]-RDG PET study. Sleep, 34, 42.

Germain, A., Shear, M. K., Hall, M., \& Buysse, D. J. (2007). Effects of a brief behavioral treatment for PTSD-related sleep disturbances: a pilot study. Behaviour Research and Therapy, 45(3), 627-632. doi:10.1016/j.brat.2006.04.009
Gibson, L. E., Holt, J. C., Fondacaro, K. M., Tang, T. S., Powell, T. A., \& Turbitt, E. L. (1999). An examination of antecedent traumas and psychiatric comorbidity among male inmates with PTSD. Journal of Traumatic Stress, 12(3), 473-484. doi:Doi 10.1023/A:1024767020280

Ginzburg, K., Koopman, C., Butler, L. D., Palesh, O., Kraemer, H. C., Classen, C. C., \& Spiegel, D. (2006). Evidence for a dissociative subtype of post-traumatic stress disorder among help-seeking childhood sexual abuse survivors. Journal of Trauma and Dissociation, 7(2), 7-27. doi:https://doi.org/10.1300/ J229v07n02_02

Giosan, C., Malta, L. S., Wyka, K., Jayasinghe, N., Evans, S., Difede, J., \& Avram, E. (2015). Sleep disturbance, disability, and posttraumatic stress disorder in utility workers. Journal of Clinical Psychology, 71(1), 72-84. doi:10.1002/jclp.22116

Gleaves, D. H., May, M. C., \& Cardena, E. (2001). An examination of the diagnostic validity of dissociative identity disorder. Clinical Psychology Review, 21(4), 577-608. doi:Doi 10.1016/S02727358(99)00073-2

Goff, A., Rose, E., Rose, S., \& Purves, D. (2007). Does PTSD occur in sentenced prison populations? A systematic literature review. Criminal Behaviour and Mental Health, 17(3), 152-162. doi:10.1002/cbm.653

Goldstein, A. N., \& Walker, M. P. (2014). The role of sleep in emotional brain function. Annual Review of Clinical Psychology, 10, 679-708. doi:10.1146/annurevclinpsy-032813-153716

Gosein, V. J., Stiffler, J. D., Frascoia, A., \& Ford, E. B. (2016). Life stressors and posttraumatic stress disorder in a seriously mentally ill jail population. Journal of Forensic Sciences, 61(1), 116-121. doi:10.1111/1556-4029.12874

Green, B. L., Dass-Brailsford, P., de Mendoza, A. H., Mete, M., Lynch, S. M., DeHart, D. D., \& Belknap, J. (2016). Trauma experiences and mental health among incarcerated women. Psychological Trauma-Theory Research Practice and Policy, 8(4), 455-463. doi:10.1037/tra0000113

Green, B. L., Miranda, J., Daroowalla, A., \& Siddique, J. (2005). Trauma exposure, mental health functioning, and program needs of women in jail. Crime \& Delinquency, 51(1), 133-151. doi:10.1177/0011128704267477

Greene, C. A., Ford, J. D., Wakefield, D. B., \& Barry, L. C. (2014). Posttraumatic stress mediates the relationship between childhood victimization and current mental health burden in newly incarcerated adults. Child Abuse and Neglect, 38(10), 1569-1580. doi:10.1016/j.chiabu.2014.07.006

Gulec, M., Kalafat, T., Boysan, M., \& Barut, Y. (2013). Psychometric Properties of the Turkish Version of the Posttraumatic Cognitions Inventory (PTCI) in a Non-Clinical Sample. Noropsikiyatri Arsivi-Archives of Neuropsychiatry, 50(2), 147153. doi:10.4274/npa.y6336

Haaland, V. O., \& Landro, N. I. (2009). Pathological dissociation and neuropsychological functioning in borderline personality disorder. Acta Psychiatrica Scandinavica, 119(5), 383-392. doi:10.1111/j.1600-0447.2008.01323.x

Habukawa, M., Uchimura, N., Maeda, M., Kotorii, N., \& Maeda, H. (2007). Sleep findings in young adult patients with posttraumatic stress disorder. Biological Psychiatry, 62(10), 1179-1182. doi:10.1016/j.biopsych.2007.01.007

Hansen, M., Mullerova, J., Elklit, A., \& Armour, C. (2016). Can the dissociative PTSD subtype be identified across two distinct trauma samples meeting caseness for PTSD? Social Psychiatry and Psychiatric Epidemiology, 51(8), 1159-1169. doi:10.1007/ s00127-016-1235-2 
Hansen, M., Ross, J., \& Armour, C. (2017). Evidence of the dissociative PTSD subtype: A systematic literature review of latent class and profile analytic studies of PTSD. Journal of Affective Disorders, 213, 59-69. doi:10.1016/j.jad.2017.02.004

Harvey, A. G. (2008). Insomnia, psychiatric disorders, and the transdiagnostic perspective. Current Directions in Psychological Science, 17(5), 299-303. doi:10.1111/j.1467-8721.2008.00594.x

Hasler, B. P., Insana, S. P., James, J. A., \& Germain, A. (2013). Evening-type military veterans report worse lifetime posttraumatic stress symptoms and greater brainstem activity across wakefulness and REM sleep. Biological Psychology, 94(2), 255-262. doi:10.1016/j.biopsycho.2013.06.007

Henrichs, J., \& Bogaerts, S. (2012). Correlates of posttraumatic stress disorder in forensic psychiatric outpatients in the Netherlands. Journal of Traumatic Stress, 25(3), 315-322. doi:10.1002/jts.21706

Ho, F. Y. Y., Chan, C. S., \& Tang, K. N. S. (2016). Cognitive-behavioral therapy for sleep disturbances in treating posttraumatic stress disorder symptoms: A meta-analysis of randomized controlled trials. Clinical Psychology Review, 43, 90-102. doi:10.1016/j. cpr.2015.09.005

Horne, J. A., \& Ostberg, O. (1975). A self-assessment questionnaire to determine morningness eveningness in human circadian rhythms. International Journal of Chronobiology, 4(2), 97-110.

Huang, G. P., Zhang, Y. L., Momartin, S., Cao, Y. P., \& Zhao, L. (2006). Prevalence and characteristics of trauma and posttraumatic stress disorder in female prisoners in China. Comprehensive Psychiatry, 47(1), 20-29. doi:10.1016/j. comppsych.2005.04.004

Jordan, B. K., Schlenger, W. E., Fairbank, J. A., \& Caddell, J. M. (1996). Prevalence of psychiatric disorders among incarcerated women .2. Convicted felons entering prison. Archives of General Psychiatry, 53(6), 513-519.

Kaba, F., Solimo, A., Graves, J., Glowa-Kollisch, S., Vise, A., MacDonald, R., . . Venters, H. (2015). Disparities in mental health referral and diagnosis in the New York City Jail Mental Health Service. American Journal of Public Health, 105(9), 1911-1916. doi:10.2105/Ajph.2015.302699

Kadak, M. T., Nasiroglu, S., Boysan, M., \& Aydin, A. (2013). Risk factors predicting posttraumatic stress reactions in adolescents after 2011 Van earthquake. Comprehensive Psychiatry, 54(7), 982-990. doi:10.1016/j.comppsych.2013.04.003

Karatzias, T., Power, K., Woolston, C., Apurva, P., Begley, A., Mirza, K., ... Purdie, A. (2017). Multiple traumatic experiences, posttraumatic stress disorder and offending behaviour in female prisoners. Criminal Behaviour and Mental Health. doi:10.1002/ cbm.2043

Khachatryan, D., Groll, D., Booij, L., Sepehry, A. A., \& Schutz, C. G. (2016). Prazosin for treating sleep disturbances in adults with posttraumatic stress disorder: a systematic review and metaanalysis of randomized controlled trials. General Hospital Psychiatry, 39, 46-52. doi:10.1016/j.genhosppsych.2015.10.007

Kilpatrick, D. G., Resnick, H. S., Milanak, M. E., Miller, M. W., Keyes, K. M., \& Friedman, M. J. (2013). National estimates of exposure to traumatic events and PTSD prevalence using DSM-IV and DSM-5 criteria. Journal of Traumatic Stress, 26(5), 537-547. doi:10.1002/jts. 21848

Knox, J., \& Lynn, S. J. (2014). Sleep experiences, dissociation, imaginal experiences, and schizotypy: The role of context. Consciousness and Cognition, 23, 22-31. doi:10.1016/j. concog.2013.10.007
Kobayashi, I., Boarts, J. M., \& Delahanty, D. L. (2007). Polysomnographically measured sleep abnormalities in PTSD: A meta-analytic review. Psychophysiology, 44(4), 660-669. doi:10.1111/j.1469-8986.2007.537.x

Komarovskaya, I. A., Loper, A. B., Warren, J., \& Jackson, S. (2011). Exploring gender differences in trauma exposure and the emergence of symptoms of PTSD among incarcerated men and women. The Journal of Forensic Psychiatry \& Psychology, 22(3), 395-410. doi:10.1080/14789949.2011.572989

Koren, D., Arnon, I., Lavie, P., \& Klein, E. (2002). Sleep complaints as early predictors of posttraumatic stress disorder: a 1-year prospective study of injured survivors of motor vehicle accidents. American Journal of Psychiatry, 159(5), 855-857. doi:10.1176/appi.ajp.159.5.855

Krakow, B., Artar, A., Warner, T. D., Melendrez, D., Johnston, L., Hollifield, M., ... Koss, M. (2000). Sleep disorder, depression, and suicidality in female sexual assault survivors. Crisis, 21(4), 163-170. doi:10.1027//0227-5910.21.4.163

Krakow, B., Haynes, P. L., Warner, T. D., Melendrez, D., Sisley, B. N., Johnston, L., . . Lee, S. (2007). Clinical sleep disorder profiles in a large sample of trauma survivors: An interdisciplinary view of posttraumatic sleep disturbance. Sleep and Hypnosis, 9(1), 6-15.

Krakow, B., Haynes, P. L., Warner, T. D., Santana, E., Melendrez, D., Johnston, L., .. Shafer, L. (2004). Nightmares, insomnia, and sleep-disordered breathing in fire evacuees seeking treatment for posttraumatic sleep disturbance. Journal of Traumatic Stress, 17(3), 257-268. doi:10.1023/B:JOTS.0000029269.29098.67

Krakow, B., Melendrez, D., Johnston, L., Warner, T. D., Clark, J. O., Pacheco, M., ... Schrader, R. (2002). Sleep-disordered breathing, psychiatric distress, and quality of life impairment in sexual assault survivors. Journal of Nervous and Mental Disease, 190(7), 442-452. doi:10.1097/01.NMD.0000022444.23912.D2

Krakow, B., Melendrez, D., Pedersen, B., Johnston, L., Hollifield, M., Germain, A., ... Schrader, R. (2001). Complex insomnia: Insomnia and sleep-disordered breathing in a consecutive series of crime victims with nightmares and PTSD. Biological Psychiatry, 49(11), 948-953.

Krakow, B., Melendrez, D., Warner, T. D., Clark, J. O., Sisley, B. N., Dorin, R., . . Hollifield, M. (2006). Signs and symptoms of sleep-disordered breathing in trauma survivors: A matched comparison with classic sleep apnea patients. Journal of Nervous and Mental Disease, 194(6), 433-439. doi:10.1097/01. nmd.0000221286.65021.e0

Krakow, B., Melendrez, D., Warner, T. D., Dorin, R., Harper, R., \& Hollifield, M. (2002). To breathe, perchance to sleep: sleepdisordered breathing and chronic insomnia among trauma survivors. Sleep Breath, 6(4), 189-202. doi:10.1007/s11325002-0189-7

Krakow, B., Ulibarri, V. A., Moore, B. A., \& Mclver, N. D. (2015). Posttraumatic stress disorder and sleep-disordered breathing: a review of comorbidity research. Sleep Medicine Reviews, 24, 37-45. doi:10.1016/j.smrv.2014.11.001

Krakow, B., \& Zadra, A. (2010). Imagery rehearsal therapy: Principles and practice. Sleep Medicine Clinics, 5(2), 289-298. doi:10.1016/j.jsmc.2010.01.004

Krause-Utz, A., Frost, R., Winter, D., \& Elzinga, B. M. (2017). Dissociation and alterations in brain function and structure: Implications for borderline personality disorder. Current Psychiatry Reports, 19(1). doi:10.1007/s11920-017-0757-y

Kubiak, S. P. (2004). The effects of PTSD on treatment adherence, drug relapse, and criminal recidivism in a sample of incarcerated men and women. Research on Social Work Practice, 14(6), 424-433. doi:10.1177/1049731504265837 
Kuroda, H., Wada, K., Takeuchi, H., \& Harada, T. (2013). PTSD score, circadian typology and sleep habits of people who experienced the Great Hanshin-Awaji Earthquake 17 years ago. Psychology (Savannah, Ga.), 4(2), 106-110. doi:10.4236/psych.2013.42015

Lanius, R. A., Brand, B., Vermetten, E., Frewen, P. A., \& Spiegel, D. (2012). The dissociative subtype of posttraumatic stress disorder: Rationale, clinical and neurobiological evidence, and implications. Depression and Anxiety, 29(8), 701-708. doi:10.1002/da.21889

Lanius, R. A., Wolf, E. J., Miller, M. W., Frewen, P. A., Vermetten, E., Brand, B., \& Spiegel, D. (2014). The dissociative subtype of PTSD. In M. J. Friedman, T. M. Keane, \& P. A. Resick (Eds.), Handbook of PTSD: Science and practice (pp. 234-250).

Levin, R., \& Nielsen, T. A. (2007). Disturbed dreaming, posttraumatic stress disorder, and affect distress: a review and neurocognitive model. Psychological Bulletin, 133(3), 482-528. doi:10.1037/0033-2909.133.3.482

Maher, M. J., Rego, S. A., \& Asnis, G. M. (2006). Sleep disturbances in patients with post-traumatic stress disorder: epidemiology, impact and approaches to management. CNS Drugs, 20(7), 567-590.

Malik, S., Kanwar, A., Sim, L. A., Prokop, L. J., Wang, Z., Benkhadra, K., \& Murad, M. H. (2014). The association between sleep disturbances and suicidal behaviors in patients with psychiatric diagnoses: a systematic review and meta-analysis. Syst Rev, 3 , 18. doi:10.1186/2046-4053-3-18

Maschi, T., Gibson, S., Zgoba, K. M., \& Morgen, K. (2011). Trauma and life event stressors among young and older adult prisoner. Journal of Correctional Health Care, 17(2), 160-172.

Maschi, T., Morgen, K., Zgoba, K., Courtney, D., \& Ristow, J. (2011). Age, Cumulative Trauma and Stressful Life Events, and Posttraumatic Stress Symptoms Among Older Adults in Prison: Do Subjective Impressions Matter? Gerontologist, 51(5), 675-686. doi:10.1093/geront/gnr074

Maxfield, M. G., \& Widom, C. S. (1996). The cycle of violence Revisited 6 years later. Archives of Pediatrics and Adolescent Medicine, 150(4), 390-395. doi:10.1001/ archpedi.1996.02170290056009

McFarlane, A. C. (2013). Biology not culture explains dissociation in posttraumatic stress disorder. Biological Psychiatry, 73(4), 296-297. doi:10.1016/j.biopsych.2012.11.026

McHugh, R. K., Hu, M. C., Campbell, A. N., Hilario, E. Y., Weiss, R. D., \& Hien, D. A. (2014). Changes in sleep disruption in the treatment of co-occurring posttraumatic stress disorder and substance use disorders. Journal of Traumatic Stress, 27(1), 8289. doi:10.1002/jts. 21878

Mellman, T. A., Bustamante, V., Fins, A. I., Pigeon, W. R., \& Nolan, B. (2002). REM sleep and the early development of posttraumatic stress disorder. American Journal of Psychiatry, 159(10), 16961701. doi:10.1176/appi.ajp.159.10.1696

Mellman, T. A., Knorr, B. R., Pigeon, W. R., Leiter, J. C., \& Akay, M. (2004). Heart rate variability during sleep and the early development of posttraumatic stress disorder. Biological Psychiatry, 55(9), 953-956. doi:10.1016/j.biopsych.2003.12.018

Mellman, T. A., Pigeon, W. R., Nowell, P. D., \& Nolan, B. (2007). Relationships between REM sleep findings and PTSD symptoms during the early aftermath of trauma. Journal of Traumatic Stress, 20(5), 893-901. doi:10.1002/jts.20246

Mergler, M., Driessen, M., Ludecke, C., Ohlmeier, M., Chodzinski, C., Weirich, S., ... Studygrp, T. (2017). Relationships between a dissociative subtype of PTSD and clinical characteristics in patients with substance use disorders. Journal of Psychoactive Drugs, 49(3), 225-232. doi:10.1080/02791072.2017.1296209
Messina, N., Burdon, W., Hagopian, G., \& Prendergast, M. (2004). One year return to custody rates among co-disordered offenders. Behavioral Sciences and the Law, 22(4), 503-518. doi:10.1002/bsl.600

Messina, N., \& Calhoun, S. (2014). Trauma-informed treatment decreases posttraumatic stress disorder among women offenders. Journal of Trauma \& Dissociation, 15(1), 6-23. doi:10 $.1080 / 15299732.2013 .818609$

Messina, N., \& Grella, C. (2006). Childhood trauma and women's health outcomes in a California prison population. American Journal of Public Health, 96(10), 1842-1848. doi:10.2105/ Ajph.2005.082016

Messina, N., Grella, C., Burdon, W., \& Prendergast, M. (2007). Childhood adverse events and current traumatic distress - A comparison of men and women drug-dependent prisoners. Criminal Justice and Behavior, 34(11), 1385-1401. doi:10.1177/0093854807305150

Messina, N. P., Burdon, W. M., \& Prendergast, M. L. (2003). Assessing the needs of women in institutional therapeutic communities. Journal of Offender Rehabilitation, 37(2), 89106. doi:10.1300/J076v37n02_05

Moloney, K. P., van den Bergh, B., \& Moller, L. F. (2009). Women in prison: The central issues of gender characteristics and trauma history. Public Health, 123(6), 426-430. doi:10.1016/j. puhe.2009.04.002

Mueser, K. T., Salyers, M. P., Rosenberg, S. D., Goodman, L. A., Essock, S. M., Osher, F. C., . . Comm, S. H. R. S. R. (2004). Interpersonal trauma and posttraumatic stress disorder in patients with severe mental illness: Demographic, clinical, and health correlates. Schizophrenia Bulletin, 30(1), 45-57. doi: 10.1093/oxfordjournals.schbul.a007067

Mullerova, J., Hansen, M., Contractor, A. A., Elhai, J. D., \& Armour, C. (2016). Dissociative Features in Posttraumatic Stress Disorder: A Latent Profile Analysis. Psychological TraumaTheory Research Practice and Policy, 8(5), 601-608. doi:10.1037/tra0000148

Nappi, C. M., Drummond, S. P. A., \& Hall, J. M. H. (2012). Treating nightmares and insomnia in posttraumatic stress disorder: A review of current evidence. Neuropharmacology, 62(2), 576585. doi:10.1016/j.neuropharm.2011.02.029

Nishith, P., Resick, P. A., \& Mueser, K. T. (2001). Sleep difficulties and alcohol use motives in female rape victims with posttraumatic stress disorder. Journal of Traumatic Stress, 14(3), 469-479. doi:10.1023/A:1011152405048

Oathes, D. J., \& Ray, W. J. (2008). Dissociative tendencies and facilitated emotional processing. Emotion, 8(5), 653-661. doi:10.1037/a0013442

Ozer, E. J., Best, S. R., Lipsey, T. L., \& Weiss, D. S. (2003). Predictors of posttraumatic stress disorder and symptoms in adults: a meta-analysis. Psychological Bulletin, 129(1), 52-73.

Peller, A. J., Najavits, L. M., Nelson, S. E., LaBrie, R. A., \& Shaffer, H. J. (2010). PTSD among a treatment sample of repeat DUI offenders. Journal of Traumatic Stress, 23(4), 468-473. doi:10.1002/jts.20550

Pigeon, W. R., Pinquart, M., \& Conner, K. (2012). Meta-analysis of sleep disturbance and suicidal thoughts and behaviors. Journal of Clinical Psychiatry, 73(9), e1160-1167. doi:10.4088/ JCP.11r07586

Roca, V., Hart, J., Kimbrell, T., \& Freeman, T. (2006). Cognitive function and dissociative disorder status among veteran subjects with chronic posttraumatic stress disorder: A preliminary study. Journal of Neuropsychiatry and Clinical Neurosciences, 18(2), 226-230. doi:10.1176/appi. neuropsych.18.2.226 
Ross, C. A., Joshi, S., \& Currie, R. (1991). Dissociative experiences in the general population: A factor analysis. Hospital and Community Psychiatry, 42, 297-301.

Ross, J., Banik, G., Dedova, M., Mikulaskova, G., \& Armour, C. (2017). Assessing the structure and meaningfulness of the dissociative subtype of PTSD. Social Psychiatry and Psychiatric Epidemiology. doi:10.1007/s00127-017-1445-2

Ruzich, D., Reichert, J., \& Lurigio, A. J. (2014). Probable posttraumatic stress disorder in a sample of urban jail detainees. International Journal of Law and Psychiatry, 37(5), 455-463. doi:10.1016/j.jilp.2014.02.018

Sadeh, N., \& McNiel, D. E. (2015). Posttraumatic stress disorder increases risk of criminal recidivism among justice-involve persons with mental disorders. Criminal Justice and Behavior, 42(6), 573 -586. doi:10.1177/0093854814556880

Saladin, M. E., Brady, K. T., Dansky, B. S., \& Kilpatrick, D. G. (1995). Understanding comorbidity between PTSD and substance use disorders: two preliminary investigations. Addictive Behaviors, 20(5), 643-655.

Salgado, D. M., Quinlan, K. J., \& Zlotnick, C. (2007). The relationship of lifetime polysubstance dependence to trauma exposure, symptomatology, and psychosocial functioning in incarcerated women with comorbid PTSD and substance use disorder. Journal of Trauma and Dissociation, 8(2), 9-26. doi:10.1300/ J229v08n02_02

Sanders, B., \& Green, J. A. (1994). The factor structure of the dissociative experiences scale in college students. Dissociation, 7, 23-27.

Scott, D. A., McGilloway, S., Dempster, M., Browne, F., \& Donnelly, M. (2013). Effectiveness of Criminal Justice Liaison and Diversion Services for Offenders With Mental Disorders: A Review. Psychiatric Services, 64(9), 843-849. doi:10.1176/appi. ps.201200144

Selvi, Y., Kandeger, A., Boysan, M., Akbaba, N., Sayin, A. A., Tekinarslan, E., ... Sar, V. (2017). The effects of individual biological rhythm differences on sleep quality, daytime sleepiness, and dissociative experiences. Psychiatry Research, 256, 243-248. doi:10.1016/j.psychres.2017.06.059

Semiz, U. B., Basoglu, C., Ebrinc, S., \& Cetin, M. (2008). Nightmare disorder, dream anxiety, and subjective sleep quality in patients with borderline personality disorder. Psychiatry and Clinical Neurosciences, 62(1), 48-55. doi:10.1111/j.1440-1819.2007.01789.x

Short, N. A., Allan, N. P., \& Schmidt, N. B. (2017). Sleep disturbance as a predictor of affective functioning and symptom severity among individuals with PTSD: An ecological momentary assessment study. Behaviour Research and Therapy, 97, 146153. doi:10.1016/j.brat.2017.07.014

Short, N. A., Babson, K. A., Boden, M. T., \& Bonn-Miller, M. O. (2015). Sleep quality, problematic cannabis use and posttraumatic stress symptoms among medical cannabis users. Addiction Research and Theory, 23(3), 246-252. doi:10.3 109/16066359.2014.981259

Short, N. A., Babson, K. A., Schmidt, N. B., Knight, C. B., Johnson, J., \& Bonn-Miller, M. O. (2016). Sleep and affective functioning: Examining the association between sleep quality and distress tolerance among veterans. Personality and Individual Differences, 90, 247-253. doi:10.1016/j.paid.2015.10.054

Short, N. A., Ennis, C. R., Oglesby, M. E., Boffa, J. W., Joiner, T. E., \& Schmidt, N. B. (2015). The mediating role of sleep disturbances in the relationship between posttraumatic stress disorder and self-injurious behavior. Journal of Anxiety Disorders, 35, 68-74. doi:10.1016/j.janxdis.2015.09.004
Simor, P., Csóka, S., \& Bódizs, R. (2010). Nightmares and bad dreams in patients with borderline personality disorder: Fantasy as a coping skill? European Journal of Psychiatry, 24(1), 28-37.

Sindicich, N., Mills, K. L., Barrett, E. L., Indig, D., Sunjic, S., Sannibale, C., . . Najavits, L. M. (2014). Offenders as victims: posttraumatic stress disorder and substance use disorder among male prisoners. Journal of Forensic Psychiatry \& Psychology, 25(1), 44-60. doi:10.1080/14789949.2013.877516

Soffer-Dudek, N., Lassri, D., Soffer-Dudek, N., \& Shahar, G. (2015). Dissociative absorption: An empirically unique, clinically relevant, dissociative factor. Conscious and Cognition, 36, 338-351. doi:10.1016/j.concog.2015.07.013

Soffer-Dudek, N., \& Shahar, G. (2009). What are sleep-related experiences? Associations with transliminality, psychological distress, and life stress. Consciousness and Cognition, 18(4), 891-904. doi:10.1016/j.concog.2008.07.007

Soffer-Dudek, N., \& Shahar, G. (2011). Daily stress interacts with trait dissociation to predict sleep-related experiences in young adults. Journal of Abnormal Psychology, 120(3), 719-729. doi:10.1037/a0022941

Soffer-Dudek, N., Shelef, L., Oz, I., Levkovsky, A., Erlich, I., \& Gordon, S. (2017). Absorbed in sleep: Dissociative absorption as a predictor of sleepiness following sleep deprivation in two high-functioning samples. Consciousness and Cognition, 48, 161-170. doi:10.1016/j.concog.2016.11.009

Spiegel, D., Loewenstein, R. J., Lewis-Fernandez, R., Sar, V., Simeon, D., Vermetten, E., . . . Dell, P. F. (2011). Dissociative disorders in DSM-5. Depression and Anxiety, 28(9), 824-852. doi:10.1002/da.20874

Spitzer, C., Dudeck, M., Liss, H., Orlob, S., Gillner, M., \& Freyberger, H. J. (2001). Post-traumatic stress disorder in forensic inpatients. Journal of Forensic Psychiatry, 12(1), 63-77. doi:Doi 10.1080/09585180121757

Stein, D. J., Koenen, K. C., Friedman, M. J., Hill, E., McLaughlin, K. A., Petukhova, M., . . . Kessler, R. C. (2013). Dissociation in Posttraumatic Stress Disorder: Evidence from the World Mental Health Surveys. Biological Psychiatry, 73(4), 302-312. doi:10.1016/j.biopsych.2012.08.022

Steiner, H., Garcia, I. G., \& Matthews, Z. (1997). Posttraumatic stress disorder in incarcerated juvenile delinquents. Journal of the American Academy of Child and Adolescent Psychiatry, 36(3), 357-365. doi:Doi 10.1097/00004583-19970300000014

Steuwe, C., Lanius, R. A., \& Frewen, P. A. (2012). Evidence for a dissociative subtype of PTSD by latent profile and confirmatory factor analyses in a civilian sample. Depression and Anxiety, 29(8), 689-700. doi:10.1002/da.21944

Stockdale, G. D., Gridley, B. E., Balogh, D. W., \& Holtgraves, T. (2002). Confirmatory factor analysis of single- and multiplefactor competing models of the dissociative experiences scale in a nonclinical sample. Assessment, 9, 94-106.

Swopes, R. M., Davis, J. L., \& Scholl, J. A. (2017). Treating substance abuse and trauma symptoms in incarcerated women: An effectiveness study. Journal of Interpersonal Violence, 32(7), 1143-1165. doi:10.1177/0886260515587668

Tapanci, Z., Yildirim, A., \& Boysan, M. (2018). Neurological soft signs, dissociation and alexithymia in patients with obsessivecompulsive disorder (OCD) and healthy subjects. Psychiatry Research, 260, 90-97. doi:10.1016/j.psychres.2017.11.058

Teplin, L. A., Abram, K. M., \& McClelland, G. M. (1996). Prevalence of psychiatric disorders among incarcerated women .1. Pretrial jail detainees. Archives of General Psychiatry, 53(6), 505-512. 
Teplin, L. A., McClelland, G. M., Abram, K. M., \& Weiner, D. A. (2005). Crime victimization in adults with severe mental illness: Comparison with the national crime victimization survey. Archives of General Psychiatry, 62(8), 911-921. doi:10.1001/ archpsyc.62.8.911

Tsai, J., Armour, C., Southwick, S. M., \& Pietrzak, R. H. (2015). Dissociative subtype of DSM-5 posttraumatic stress disorder in US veterans. Journal of Psychiatric Research, 66-67, 67-74. doi:10.1016/j.jpsychires.2015.04.017

van der Hart, O., van Ochten, J. M., van Son, M. J., Steele, K., \& Lensvelt-Mulders, G. (2008). Relations among peritraumatic dissociation and posttraumatic stress: A critical review. Journal of Trauma and Dissociation, 9(4), 481-505.

Van Der Kloet, D., Giesbrecht, T., Franck, E., Van Gastel, A., De Volder, I., Van Den Eede, F., ... Merckelbach, H. (2013). Dissociative symptoms and sleep parameters - an all-night polysomnography study in patients with insomnia. Comprehensive Psychiatry, 54(6), 658-664. doi:10.1016/j. comppsych.2012.12.025

van der Kloet, D., Giesbrecht, T., Lynn, S. J., Merckelbach, H., \& de Zutter, A. (2012). Sleep normalization and decrease in dissociative experiences: Evaluation in an inpatient sample. Journal of Abnormal Psychology, 121(1), 140-150. doi:10.1037/ a0024781

van der Kloet, D., Merckelbach, H., Giesbrecht, T., \& Lynn, S. J. (2012). Fragmented sleep, fragmented mind: The role of sleep in dissociative symptoms. Perspectives on Psychological Science, 7(2), 159-175. doi:10.1177/1745691612437597

van Heugten-van der Kloet, D., Giesbrecht, T., \& Merckelbach, H. (2015). Sleep loss increases dissociation and affects memory for emotional stimuli. Journal of Behavior Therapy and Experimental Psychiatry, 47, 9-17. doi:10.1016/j.jbtep.2014.11.002

van Heugten-van der Kloet, D., Huntjens, R., Giesbrecht, T., \& Merckelbach, H. (2014). Self-reported sleep disturbances in patients with dissociative identity disorder and post-traumatic stress disorder and how they relate to cognitive failures and fantasy proneness. Frontiers in Psychiatry, 5(19). doi:10.3389/ fpsyt.2014.00112

van Heugten-van der Kloet, D., Merckelbach, H., Giesbrecht, T., \& Broers, N. (2014). Night-time experiences and daytime dissociation: A path analysis modeling study. Psychiatry Research, 216(2), 236-241. doi:10.1016/j.psychres.2013.12.053

van Huijstee, J., \& Vermetten, E. (2017). The dissociative subtype of post-traumatic stress disorder: Research update on clinical and neurobiological features. In (pp. 1-20). Berlin, Heidelberg: Springer Berlin Heidelberg.

Wada, K., Kuroda, H., Nakade, M., Takeuchi, H., \& Harada, T. (2014). Epidemiological studies on the relationship between PTSD symptoms and circadian typology and mental/sleep health of young people who suffered a natural disaster, Great HanshinAwaji Earthquake. Natural Science, 6(5), 338-350. doi:10.4236/ ns.2014.65035

Walker, M. P., \& van der Helm, E. (2009). Overnight therapy? The role of sleep in emotional brain processing. Psychological Bulletin, 135(5), 731-748. doi:10.1037/a0016570

Wallace, C., Mullen, P., Burgess, P., Palmer, S., Ruschena, D., \& Browne, C. (1998). Serious criminal offending and mental disorder: Case linkage study. British Journal of Psychiatry, 172, 477-484. doi:10.1192/bjp.172.6.477
Waller, N. G., Putnam, F. W., \& Carlson, E. B. (1996). Types of dissociation and dissociative types: A taxometric analysis of dissociative experiences. Psychological Methods, 1(3), 300321. doi:Doi 10.1037/1082-989x.1.3.300

Warren, J. I., Loper, A. B., \& Komarovskaya, I. (2009). Symptom patterns related to traumatic exposure among female inmates with and without a diagnosis of posttraumatic stress disorder. Journal of the American Academy of Psychiatry and the Law, 37(3), 294-305.

Watson, D. (2001). Dissociations of the night: Individual differences in sleep-related experiences and their relation to dissociation and schizotypy. Journal of Abnormal Psychology, 110(4), 526535. doi:10.1037/0021-843X.110.4.526

Williams, S. G., Collen, J., Orr, N., Holley, A. B., \& Lettieri, C. J. (2015). Sleep disorders in combat-related PTSD. Sleep Breath, 19(1), 175-182. doi:10.1007/s11325-014-0984-y

Wolf, E. J., Lunney, C. A., Miller, M. W., Resick, P. A., Friedman, M. J., \& Schnurr, P. P. (2012). The dissociative subtype of PTSD: A replication and extension. Depression and Anxiety, 29(8), 679688. doi:10.1002/da.21946

Wolf, E. J., Miller, M. W., Reardon, A. F., Ryabchenko, K. A., Castillo, D., \& Freund, R. (2012). A latent class analysis of dissociation and posttraumatic stress disorder: Evidence for a dissociative subtype. Archives of General Psychiatry, 69(7), 698-705. doi:10.1001/archgenpsychiatry.2011.1574

Wolf, E. J., Mitchell, K. S., Sadeh, N., Hein, C., Fuhrman, I., Pietrzak, R. H., \& Miller, M. W. (2017). The Dissociative Subtype of PTSD Scale: Initial evaluation in a national sample of trauma-exposed veterans. Assessment, 24(4), 503-516. doi:10.1177/1073191115615212

Wolff, N., Frueh, B. C., Shi, J., \& Schumann, B. E. (2012). Effectiveness of cognitive-behavioral trauma treatment for incarcerated women with mental illnesses and substance abuse disorders. Journal of Anxiety Disorders, 26(7), 703-710. doi:10.1016/j.janxdis.2012.06.001

Wolff, N., \& Shi, J. (2011). Patterns of victimization and feelings of safety inside prison: The experience of male and female inmates. Crime \& Delinquency, 57(1), 29-55. doi:10.1177/0011128708321370

Woud, M. L., Verwoerd, J., \& Krans, J. (2017). Modification of cognitive biases related to posttraumatic stress: A systematic review and research agenda. Clinical Psychology Review, 54, 81-95. doi:10.1016/j.cpr.2017.04.003

Wright, K. M., Britt, T. W., Bliese, P. D., Adler, A. B., Picchioni, D., \& Moore, D. (2011). Insomnia as predictor versus outcome of PTSD and depression among Iraq combat veterans. Journal of Clinical Psychology, 67(12), 1240-1258. doi:10.1002/jclp.20845

Yargic, L. I., Tutkun, H., \& Sar, V. (1995). The reliability and validity of the Turkish version of the Dissociative Experiences Scale. Dissociation, 8, 10-13

Yildirim, A., \& Boysan, M. (2017). Heterogeneity of sleep quality based on the Pittsburgh Sleep Quality Index in a community sample: a latent class analysis. Sleep and Biological Rhythms, 15(3), 197-205. doi:10.1007/s41105-017-0097-7

Yıldırım, A., Boysan, M., \& Yılmaz, O. (2017). The mediating role of pathological worry in associations between dissociative experiences and sleep quality among health staff. Sleep and Hypnosis. doi:http://dx.doi.org/10.5350/Sleep.Hypn.2017.19.0152

Zlotnick, C., Johnson, J., \& Najavits, L. M. (2009). Randomized controlled pilot study of cognitive-behavioral therapy in a sample of incarcerated women with substance use disorder and PTSD. Behavior Therapy, 40(4), 325-336. doi:10.1016/j. beth.2008.09.004 